\title{
Cross-Impacts Analysis Development and Energy Policy Analysis Applications
}

December 1986

Prepared for the U.S. Department of Energy under Contract DE-AC06-76RLO 1830

Pacific Northwest Laboratory Operated for the U.S. Department of Energy by Battelle Memorial Institute 


\title{
DISCLAIMER
}

This report was prepared as an account of work sponsored by an agency of the United States Government. Neither the United States Government nor any agency thereof, nor Battelle Memorial Institute, nor any of their employees, makes any warranty, expressed or implied, or assumes any legal liability or responsibility for the accuracy, completeness, or usefulness of any information, apparatus, product, or process disclosed, or represents that its use would not infringe privately owned rights. Reference herein to any specific commercial product, process, or service by trade name, trademark, manufacturer, or otherwise, does not necessarily constitute or imply its endorsement, recommendation, or favoring by the United States Government of any agency thereof, or Battelle Memorial Institute. The views and opinions of authors expressed herein do not necessarly state or reflect those of the United States Government or any agency thereof, or Battelle Memorial Institute.

\author{
PACIFIC NORTHWEST LABORATORY \\ operated by \\ BATTELLE \\ for the \\ UNITED STATES DEPARTMENT OF ENERGY \\ under Contract DE-AC06-76RLO 1830
}

\begin{tabular}{|c|c|}
\hline \multicolumn{2}{|c|}{$\begin{array}{l}\text { Printed in the United States of America } \\
\text { Available from } \\
\text { National Technical Information Service } \\
\text { United States Department of Commerce } \\
5285 \text { Port Royal Road } \\
\text { Springfield, Virginia } 22161\end{array}$} \\
\hline \multicolumn{2}{|c|}{$\begin{array}{l}\text { NTIS Price Codes } \\
\text { Microfiche A01 }\end{array}$} \\
\hline \multicolumn{2}{|c|}{ Printed Copy } \\
\hline Pages & $\begin{array}{l}\text { Price } \\
\text { Codes }\end{array}$ \\
\hline 001-025 & $\mathrm{A} 02$ \\
\hline 026-050 & $\mathrm{A} 03$ \\
\hline $051-075$ & $\mathrm{~A} 04$ \\
\hline $076-100$ & A05 \\
\hline $101-125$ & $\mathrm{~A} 06$ \\
\hline $126-150$ & $\mathrm{~A} 07$ \\
\hline $151-175$ & A0B \\
\hline $176-200$ & A09 \\
\hline $201-225$ & A010 \\
\hline $226-250$ & A011 \\
\hline $251-275$ & A012 \\
\hline $276-300$ & A013 \\
\hline
\end{tabular}




\author{
J. M. Roop \\ R. M. Scheer
G. S. Stacey $(a)$
}

December 1986

Prepared for the U.S. Department of Energy under Contract DE-AC06-76RL0 1830

Pacific Northwest Laboratory

Richland, Washington 99352

(a) Battelle Columbus Laboratory Columbus, Ohio 43201 



\section{EXECUTIVE SUMMARY}

The purpose of this report is to describe the cross-impact analysis process and microcomputer software that Pacific Northwest Laboratory (PNL) and its subcontractors have developed for the Office of Policy, Planning, and Analysis (PPA) of the U.S. Department of Energy (DOE). First introduced in 1968, crossimpact analysis is a technique that produces scenarios of future conditions and possibilities. It has undergone considerable modification since its introduction and is still the subject of much experimentation and revision. PNL has investigated its usefulness and applicability to energy policy analysis.

Why investigate cross-impact analysis when there are already several other forecasting techniques available to DOE for conducting energy policy analysis? Cross-impact analysis has several unique attributes that make it a tool worth examining, especially in the current climate when the outlook for the economy and several of the key energy markets is uncertain.

Cross-impact analysis provides special capability for energy policy studies because it is different from and complements the econometric, engineering, systems dynamics, or trend approaches that are already in use at DOE. Crossimpact analysis does not produce detailed forecasts but is a tool that produces self-consistent scenarios in the broadest sense and can include interaction between the economy, technology, society and the environment. Energy policy analyses that couple broad scenarios of the future with detailed forecasting can produce more powerful results than scenario analysis or forecasts can produce alone. Coupling the approaches can quantify the impacts of alternative energy policies under a wide range of future economic, societal, and technological conditions, possibilities and contingencies.

Cross-impact analysis shows considerable promise as a policy analysis tool as evidenced by the following features. Cross-impact analysis:

- makes explicit the assumptions and judgments used to produce scenarios of the future;

- provides a structured analysis process for testing opposing viewpoints regarding future conditions, events, and possibilities; 
- treats future outcomes probabilistically so that uncertainty can be analyzed directly;

- incorporates important factors for analyzing the future such as technological change, lifestyles, or institutional change, for which little historical data is available;

- emphasizes consensus by involving three or more analysts with varying backgrounds and expertise in the process; and

- operates in-house using specially designed microcomputer software called DOECIM (DOE Cross-Impact Model).

The six-step cross-impact analysis process is shown graphically in Figure ES.1. Section 2.0 of this report presents an overview to this process and each step is discussed in the separate sections that follow the overview. cross-impact jargon like "descriptors", "a priori probabilities", "conditional probabilities", "base-case matrix", "impact scale", and "computer simulations" are defined for the reader in the Introduction, Section 1.0 .

A sample scenario analysis was conducted as a part of this effort and is presented and discussed alongside the process description. We analyzed future energy-use intensity and efficiency in the industrial sector of the U.S. economy in 1995. Lessons learned from this sample study are presented as a part of the process description.

This project included a review of the cross-impact literature (a bibliography can be found in Appendix A), critiques of other cross-impact approaches, development of a new computational algorithm (described in Appendix D), and a sample scenario analysis. Based on the results of these activities we conclude the following:

- Cross-impact analysis is most usefut when applied to broad-brush, scoping studies where future scenarios can define the major issues and identify topics for more detailed analysis. Because the approach relies heavily on the opinions of experts about the future, it is less useful than other techniques if the forecast horizon: is less than ten years; is not expected to undergo significant change or turbulence; and is not particularly uncertain. 


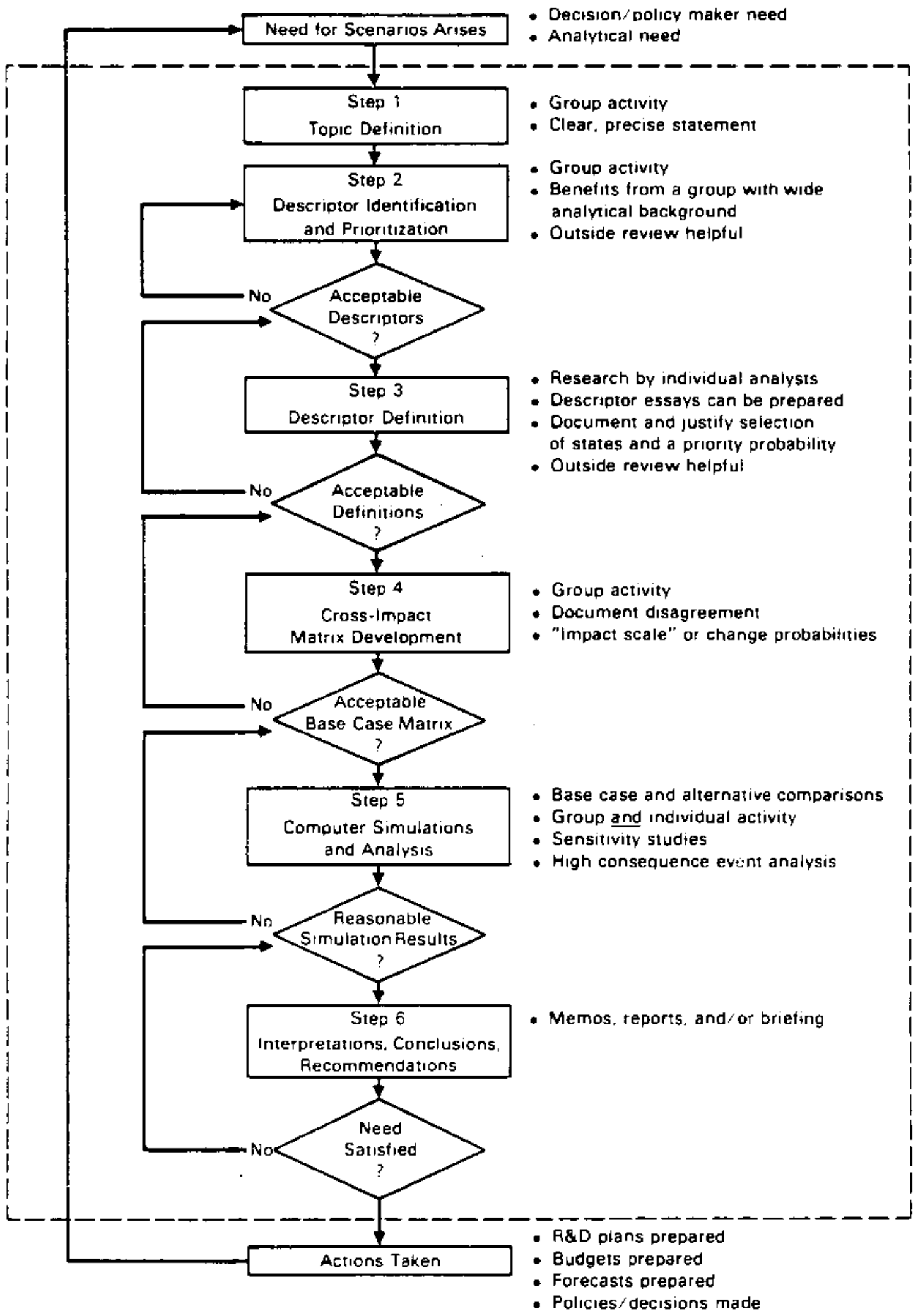

FIGURE ES.1 Cross-Impact Analysis Process 
- The computer software that has been developed, called DOECIM, operates on an IBM-PC or compatible microcomputer with at least $348 \mathrm{~K}$ of memory and two disk drives. The software is menu driven and employs full prompting at all times for ease of use. The software includes an instruction guide and three program diskettes. DOECIM has been designed to follow more closely the theory of joint probability estimation than do other scenario generation procedures.

- The first two steps in cross-impact analysis, topic definition and descriptor identification, are best accomplished in workshop settings attended by eight or less participants who are experts in various aspects of the problem. In the example discussed below, energy policy analysis, the workshops included experts on: technology, institutions, economics, human behavior, etc. These workshops should be highly structured meetings led by a facilitator to keep the meeting on track and ensure that all individuals participate.

- The state-of-the-art in cross-impact analysis is not fixed but is in a state of flux and much more development is not only possible but needed before the methodology can lay any strong claim to rigor. DOECIM has advanced the state-of-the-art in several important respects. For one, the computational algorithm that produces the most likely scenarios is based on conditional probabilities of joint events, unlike other scenario development techniques. In addition, analysts have considerable flexibility in structuring the process and using the software to address analytical needs. The six-step process provides a useful structure for many analytical inquiries even if the analyst does not intend to develop future scenarios or use the DOECIM software. Similarly, the experienced analyst could forego the six-step process and work directly with the software if scenario analysis is needed under short deadlines.

Finally, the DOECIM software is available now in a form that can be used easily on IBM-PC or compatible microcomputers. DOECIM can be particularly useful for examining contingencies in energy markets caused by uncertainty surrounding future world oil prices. Scenario analysis of future conditions and possibilities using DOECIM can provide added insight to ongoing analyses because the cross-impact approach can draw upon experts to supplement historical 
data with information on current trends, and expected breakthroughs or turnarounds in market conditions. We recommend that DOE use DOECIM to gain experience with the tool and so that the benefits of policy analyses that couple broad scenarios with detailed forecasts can be realized. 


\section{ACKNOWLEDGMENTS}

We wish to recognize the contributions of a number of analysts and experts in the course of this project. In addition to the staff of the office of Policy Integration (OPI), particularly Barry McNutt, we recognize the contribution of Robert C. Marlay, currently with the Office of Energy Research of the Department of Energy (DOE), in the initial workshops for the industrial sector. This project owes special recognition to H. T. McAdams, for his contribution of numerous thoughtful essays on the cross-impact approach, the conversion of qualitative impacts to probabilities, and the computation of the probabilities associated with a particular scenario. 


\section{CONTENTS}

EXECUTIVE SUMMARY

ACKNOWLEDGEMENTS

1.0 INTRODUCTION

1.1 WHY CROSS-IMPACTS ANALYSIS

1.2

1.2 CROSS-IMPACT ANALYSIS TERMINOLOGY • • • • • • • 1.2

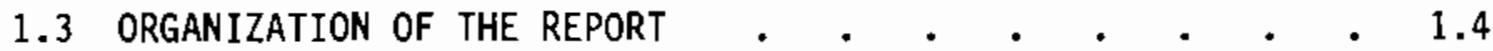

2.0 CROSS-IMPACT ANALYSIS PROCESS OVERVIEW • • • • • • • • • 2.1

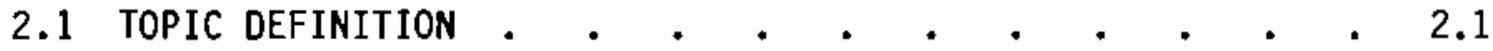

2.2 DESCRIPTOR IDENTIFICATION AND PRIORITIZATION $\quad 2.2$

2.3 DESCRIPTOR DEFINITION • • • • • • • • • • • • 2.2

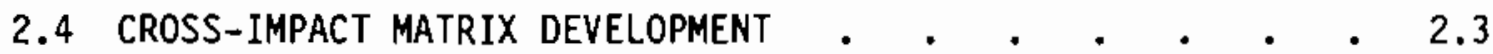

2.5 COMPUTER SIMULATION AND ANALYSIS • • • • • • • • 2.4

2.6 INTERPRETATION, CONCLUSIONS, RECOMMENDATIONS $\quad$ • $\quad$ • 2.4

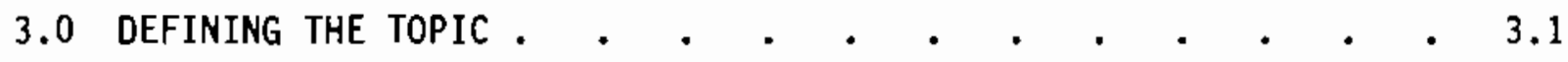

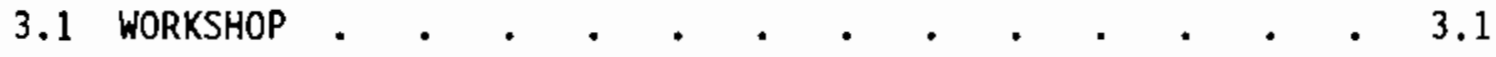

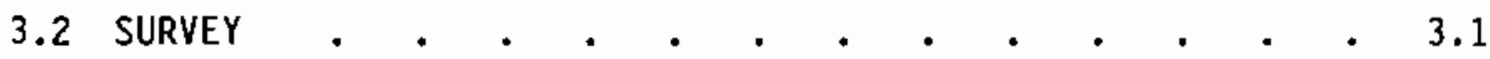

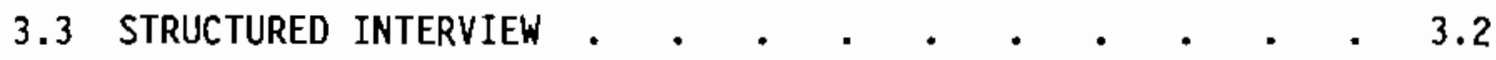

3.4 TOPIC CONTENT . . . . . . . . . . . . . . 3.2

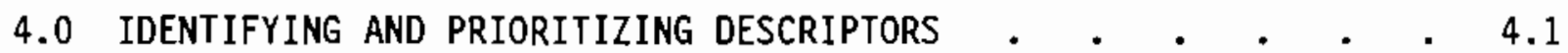

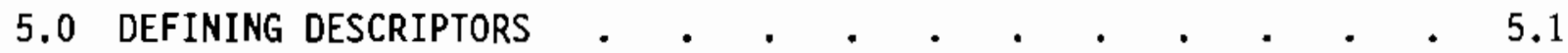

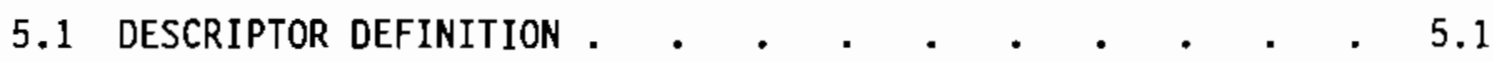

5.2 RATIONALIZING THE DESCRIPTOR • • • • . • . 5.2

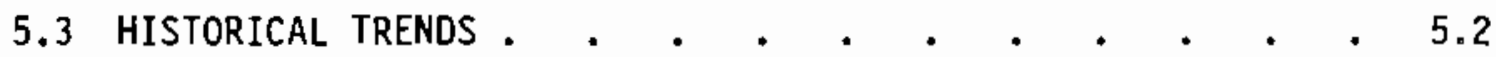

5.4 CURRENT SITUATION . $. \quad . \quad$. . . . . . . . . . 5.3

5.5 FUTURE PROSPECTS . . . . . . . . . . . . . . 5.3 




6.0 DEVELOPING CROSS-IMPACT MATRICES . • • • • • • • • • 6.1

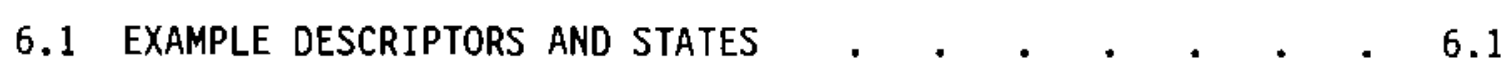

6.2 BUILDING THE CROSS-IMPACTS MATRIX . . . . . . . . 6.3

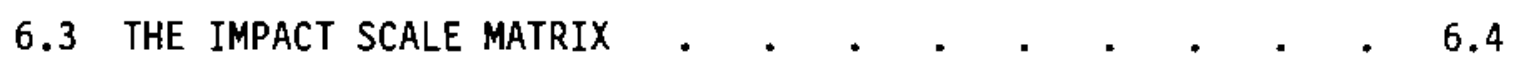

6.4 PROBLEMS THAT APPLY TO CROSS IMPACT ANALYSIS • • • $\quad 6.5$

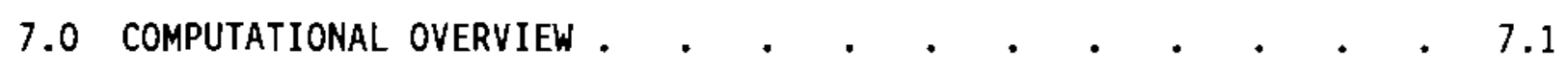

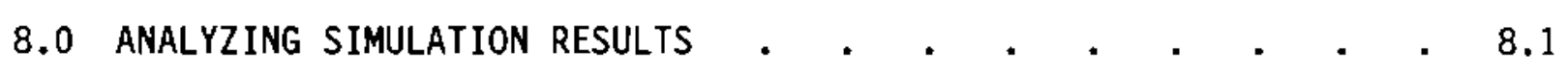

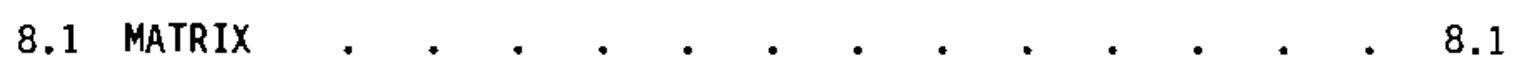

8.2 DRIVER AND DRIVEN DESCRIPTOR STATES $• \cdot \quad \cdot \quad \cdot \quad \cdot \quad \cdot \quad 8.1$

8.3 BASE-CASE • • • • • • • • • • • • 8.2

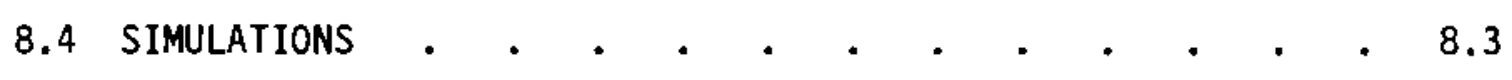

8.4.1 Impact values . . . . • • • • • 8.3

8.4.2 A Priori Probabilities. . . . . . . 8.3

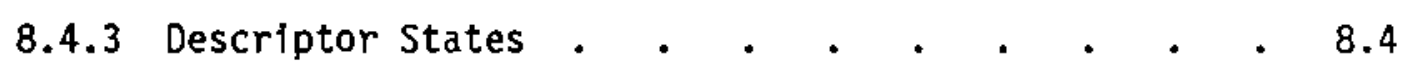

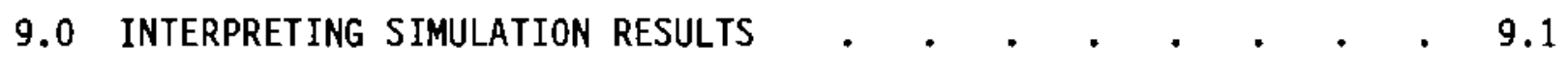

9.1 WORKSHOPS . . . . . . . . . . . . 9.1

9.2 FORECASTS . . . . . . . . . . . . . 9.2

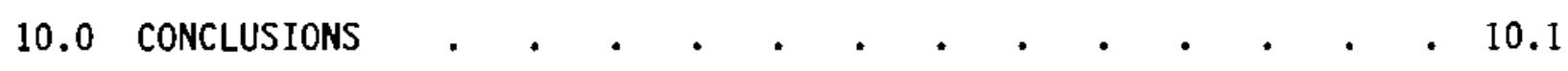

APPENDIX A - CROSS-IMPACTS ANALYSIS BIBLIOGRAPHY • • • • • • • A.1

APPENDIX B - SAMPLE SIMULATION OUTPUT • • • • • • • • • •

APPENDIX C - SAMPLE DESCRIPTOR ESSAYS • • • • • • • • • • c c.1

APPENDIX D - "LAMP POST": A COMPUTATIONAL ALGORITHM • • • • • • 0.1 


\subsection{INTRODUCTION}

The purpose of this study is to develop a cross-impact analysis tool for policy analysis studies at the U.S. Department of Energy (DOE). Cross-impact analysis is a technique for forecasting future events, conditions, events, and possibilities. Like other forecasting tools such as trend analysis, econometric analysis or systems dynamics, cross-impact analysis can be applied to policy analysis questions and makes use of historical data and existing forecasts. Unlike the other approaches mentioned, cross-impact analysis can analyze variables for which little historical data is avallable such as technological change or lifestyles, and uses expert judgment about the future as an explicit part of its input data.

Cross-impact analys is has undergone considerable modification since its introduction in 1968 and is still the subject of much experimentation and revision. We compiled a bibliography with over 100 entries concerning crossimpact analysis theory and practice indicating significant interest in the approach in the scientific and professional literature. The general conclusion to be drawn from a review of this literature is that cross-impact analysis is not fixed but is in a state of flux and that much more development is not only possible but needed before the methodology can lay any strong claim to rigor.

Battelle Memorial Institute developed a computerized cross-impact analys is tool called BASICS that has been used extensively for private sector clients to develop future scenarios of market conditions and opportunities for the banking and printing industries among others. We began our development of a cross-impact energy policy analysis tool for DOE with BASICS.

Not surprising, given the evolving state-of-the-art in cross-impact analysis, we identified several improvements to make to the computational algorithm of BASICS. The revised algorithm, called LAMP POST, is described in Section 7 and Appendix $D$ and is contained in the new microcomputer crossimpact analysis tool we developed for DOE called DOECIM (DOE Cross-Impact Mode 1).

DOECIM operates on an IBM-PC or compatible microcomputer with at least $348 \mathrm{~K}$ of memory and two disk drives. The software is menu driven and employs 
full prompting at all times for ease of use. DOECIM software is available and consists of three floppy disks. An instruction guide accompanies the microcomputer software.

\subsection{WHY CROSS-IMPACT ANALYSIS?}

Why investigate cross-impact analysis when there are other forecasting techniques already available to DOE? What added benefit can be derived? How is cross-impact different from other modeling approaches?

Cross-impact analysis provides special capability for energy policy studies because it is different from and complements the econometric, engineering, trend, and systems dynamic approaches that are already in use at DOE. Crossimpact analysis does not produce detailed forecasts, it does produce selfconsistent scenarios of future conditions and possibilities in the broadest sense. When coupled with detailed forecasts, these scenarios can address a wide range of economic, technological, societal or environmental contingencies that may result from or affect DOE policies.

Coupling broad scenarios with detailed forecasts produces more valuable confirmation and insight than could be gained from using either approach alone. The cross-impact approach can produce a wide range of alternative outcomes or futures for important variables. Because cross-impact analysis collects and synthesizes expert judgment on the likelihood of expected future events, the uncertainty surrounding future world oil prices, economic growth, or the adoption of new technology can be analyzed directly.

\subsection{CROSS-IMPACT ANALYSIS TERMINOLOGY}

Cross-impact analysis has a terminology of its own.

Topic is the subject matter of a cross-impact analysis exercise and includes the variables to be forecast and the forecast time horizon. The topic structures the analysis by saying what is and is not involved.

Descriptors are the factors selected by experts as being important to understanding the topic. Descriptors can be variables, issues, public policies or trends involving economic, political, sociological, technological, institutional, demographic, etc. data. 
Descriptor States refer to possible alternative future outcomes for descriptors. Descriptor states for Technological Change, for example, could be "more rapid than today", "equal to today" and "less than today". Quantitative measures of where one state ends and another begins are important to develop, if it is possible to do so. Sometimes a descriptor such as lifestyles has little quantitative data to support analysis. However, crossimpact analysis can still proceed in such instances as long the descriptor and its states are defined to the satisfaction of the study participants.

A Priori Probabilities are the likelihood of future occurrence assigned to the descriptor states by the experts and associated with the time frame of study. Descriptor states are mutually exclusive so the a priori probabilities for any descriptor must sum to one. Sample a priori probabilities for the Technological Change descriptor referred to earlier could be $40 \%$ for "more rapid than today", $40 \%$ for "equal to today", and $20 \%$ for "less than today".

Conditional Probabilities are the likelihood of future occurrence of joint events between descriptor states. For example, consider Economic Growth along with Technological change in a two-descriptor model. Suppose that the descriptor states and a priori probabilities for economic growth are $30 \%$ for "greater than 4\% per year"; $40 \%$ for "2-4\% per year"; and $20 \%$ for "less than 2\% per year". Conditional probabilities are the likelihood of occurrence of joint events such as technological change "more rapid than today" given economic growth "greater than $4 \%$." Conditional probabilities are the changes in a priori probabilities that result from the interaction between the descriptor states. The interaction can have positive impacts (conditionals greater than a priori), negative impacts, (conditionals less than a priori), or no effect. Input from other analysis, data, and trends combines with expert judgment to determine the sign and size of the change in a priori probabilities that result from their interaction with other descriptor states.

Cross-Impact Matrix is the set of all conditional probabilities among descriptor states. A sample matrix of two descriptors, with three states each, has 36 cells. Only half the cells in the example represent conditional probabilities as descriptor states of the same descriptor do not interact.

Impact value is a number that experts can assign to quantity the interaction effect between descriptors as an alternative to determining 1.3 
conditional probabilities directly. Impact values can range from minus 30 to plus 30, with minus 30 representing a strong negative effect of one descriptor state on another, plus 30 a strong positive effect, and 0 is no effect. Impact values rather than conditional probabilities can be entered in the cells of a cross-impact matrix. The two approaches are included because some analysts prefer using conditional probabilities, while other analysts find it easier to use impact values as an intermediate step and let the computer determine conditional probabilities.

Computer simulations are used to soive the cross-impact matrix for the most likely scenarios. Each of the top ten scenarios consists of the predicted occurrence of one descriptor state for each descriptor in the cross-impact model of the topic being studied. In our two-descriptor example, a possible "most likely" scenario might be Technological Change "more rapid than today" and Economic Growth "2 to 4\% per year."

A scenario from among the top ten, perhaps the most likely, is typically selected as the base-case scenario. Alternative computer simulations can be run to analyze how changes in cross-impacts, a priori probabilities, or new descriptors affect the base-case scenario. These additional computer simulations constitute what is typically called sensitivity analysis.

\subsection{ORGANIZATION OF THE REPORT}

The organization of the report corresponds to the overview of the crossimpact analysis process contained in Section 2.0. Following the overview section, are sections concerning each step in the cross-impact analysis process. Section 3.0 discusses topic definition, Section 4.0 discusses descriptor identification, Section 5.0 discusses descriptor definition, Section 6.0 discusses cross-impact matrix development, Section 7.0 discusses the LAMP POST computational algorithm, Section 8.0 discusses scenario analysis and Section 9.0 discusses interpreting scenario analysis results. Section 10.0 presents conclusions and recommendations.

Several appendices are included. Appendix $A$ is a bibliography of relevant cross-impact analysis articles. Appendix $B$ contains sample scenario analysis output including a topic statement, a list of descriptor and descriptor states, a cross-impact matrix with conditional probabilities and one with impact values, 
a base-case scenario simulation, and several sensitivity simulations. Appendix C contains two sample descriptor essays which are research papers that provide the rationale for selecting descriptor states and a priori probabilities. Appendix $D$ contains a detailed description of the LAMP POST computational algorithm. 
. 


\subsection{CROSS-IMPACT ANALYSIS PROCESS OVERVIEW}

This section describes in broad terms the cross-impact analysis process that we developed for DOE; subsequent sections provide the step-by-step details.

Cross-impact analysis consists of both group analysis and individual research. By group analysis we mean highly structured meetings where the collective judgment of experts about the future are obtained and input into the computer simulation model. Individuals conduct research at several steps in the process to develop information that assists the group of experts to make judgments about the interrelationship among the factors that have been selected as being important to future outcomes.

Figure 2.1 diagrams the cross-impact analysis process step-by-step. As shown, the process begins when the need for scenarios about the future arises. Such needs arise when policy makers want information on the consequences of alternative government actions on future conditions or possibilities; or when policy analysts want to broaden their perspective by using another technique in their approach to the problem. The remaining sections of this section address the six steps of the cross-impact analysis process shown in Figure 2.1.

\subsection{TOPIC DEFINITION}

Topic definition is group activity involving, preferably, eight or less analysts. If possible, it is desirable to have the policy maker (or a representative) present at the meeting where the topic is defined to at least kick-off the session and emphasize the major policy issues.

Topic definition meetings can take from four to eight hours depending on the complexity of the policy and the number of people in attendance (the more people the longer it typically takes). We have found it useful to have a meeting facilitator present at these sessions to focus the discussion and keep the group on track. It has also been useful for one of the analysts to assume lead responsibility for the topic definition exercise so that disagreements can be resolved quickly if consensus does not occur.

The output of topic definition meetings is a clear, concise statement of what is to be studied. This can usually be accomplished in two paragraphs or 


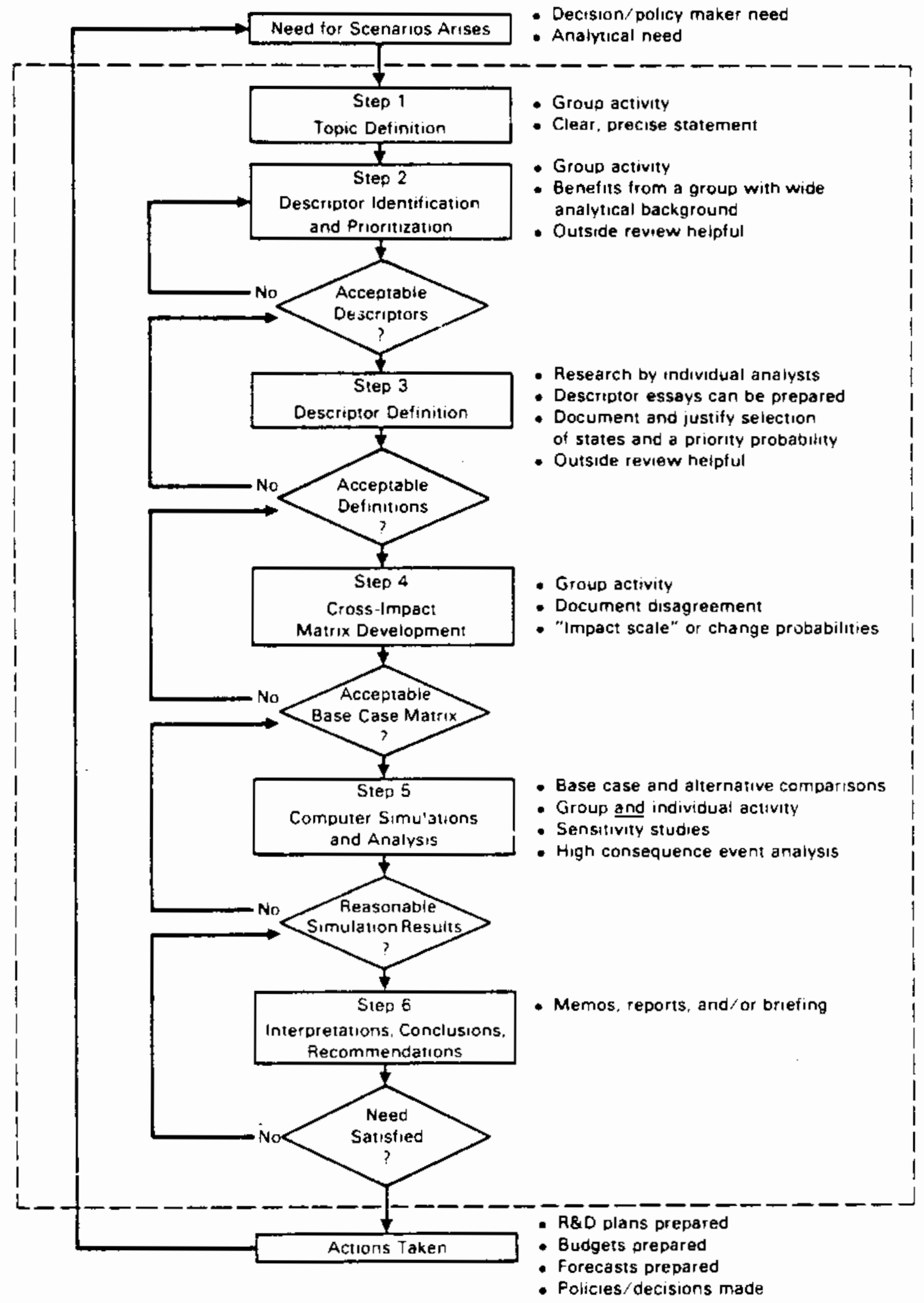

FIGURE 2.1 Cross-Impact Analys is Process 
less. Topic statements should include the variables to be forecast, the time frame of the study, and the major policy issues to be addressed.

\subsection{DESCRIPTOR IDENTIFICATION AND PRIORITIZATION}

This step is another group activity that works best if it involves the same group of analysts that developed the topic statement and follows closely behind the topic definition meeting. In this meeting, the group brainstorms a list of factors that fully describe all of things important to understanding, analyzing, and forecasting the topic under study.

Typically, the group spends several hours creating a "laundry list" of descriptors in discussions that are unconstrained, free-wheeling and nonjudgmental. The group then assesses the relative importance of various descriptors in order to select a manageable amount of high priority items. Five to fifteen high priority descriptors per matrix is typical. The DOECIM software works best with ten descriptors or less.

We have found it useful to solicit input from analysts from outside the group that attend the meeting, particularly if the initial group consists of only one or two types of analysts (such as all engineers and physical scientists, and no social scientists). This helps to broaden the analytical perspective and reduce bias that may be present in policy analyses based on a single discipline.

\subsection{DESCRIPTOR DEFINITION}

Descriptor definition involves individual analysts researching what is known about the descriptor. Analysts may produce a 3-5 page research paper that investigates historical trends, current status, and future projections for the descriptor. This paper provides the rationale for selection of descriptor states and a priori probabilities for those states. Depending on time, budget and knowledge of the analysts, essays can be prepared on all, some, or none of the descriptors.

Selection of descriptor states and a priori probabilities is one of the most critical steps in the cross-impact analysis process. While the judgments are made by individuals, selections should be reviewed and agreed to by the other analysts in the group. In many cases, input from analysts outside the group on particular descriptors may be helpful. 


\subsection{CROSS-IMPACT MATRIX DEVELOPMENT}

Developing cross-impact matrices is a group analysis activity where collective judgments are made regarding the conditional probability of jointevents. This activity quantifies the effect that the occurrence of one descriptor state has on the a priori probability of another state occurring. Typically, it will take three analysts from four to eight hours to develop a matrix that has fifteen descriptors with three descriptor states each.

The greater the number of analysts, the longer it typically takes to build a matrix.

Using DOECIM, there are two ways for analysts to quantify the magnitude of the interaction between descriptors: using conditional probabilities or impact values. With the first approach, collective judgments about conditiona? probabilities are entered into the cells of the matrix directly. With the second approach, analysts can enter an impact scale with values ranging from minus thirty, to zero, to plus thirty. Minus thirty indicates that the occurrence of one descriptor strongly decreases the likelihood of the second descriptor state occurring; zero indicates no impact; and plus thirty strongly increases the likelihood of the second descriptor state occurring.

Because a simple equation ties the impact scale and conditional probabilities together (making it possible to map directly from an impact scale matrix to a conditional probability matrix), the only difference in the two approaches is ease of use. Some analysts find it easier to think about cross-impacts in terms of scaling factors, others prefer to think in terms of conditional probabilities.

When filling out a cross-impact matrix, it is rare for there to be quick consensus among analysts about the size and direction of the interrelationships. Be prepared to spend more time than you think on this activity. This is especially true when mọre than three analysts are involved. The best approach for overcoming this difficulty is for the lead analyst to be given responsibility for making decisions when differences arise, and for a record to be kept of "minority" viewpoints so that alternative values can be revisited later in the analysis process. 


\subsection{COMPUTER SIMULATIONS AND ANALYSIS}

This activity involves solving the cross-impact matrix so as to produce the ten highest probability scenarios. Typically, the most likely scenario is selected as a "base-case" and compared to one or two alternatives. Alternative cases can reflect "minority viewpoints" mentioned in Section 2.4, and can include new descriptors that represent high consequence - low probability events such as wars, environmental disasters, technology breakthrough, etc.

Considerable effort is often required to develop a satisfactory base case. Because it can take several days for DOECIM to solve a model with greater that ten descriptors, it is useful to conduct this analysis carefully and to develop a clear analysis plan. Output from the computer simulations should be reviewed and discussed by the group.

\subsection{INTERPRETATION, CONCLUSIONS, RECOMMENDATIONS}

The final step is to determine the meaning of the scenarios for the energy policy analysis topic. The amount of effort this takes depends on the complexity of the policy question. Reports, memoranda and briefings are prepared to communicate the findings and recommendations to policy makers, other analysts, or other interested parties. 


\subsection{DEFINING THE TOPIC}

The definition of the topic is a critical step to producing useful forecasts on a subject. It establishes the scope of the analysis and clarifies the specific questions that are to be addressed by the work. It also serves to establish clearly among all the participants and users of the results what the objective of the analysis is and what is expected to be included in the forecast model framework. Experience shows that a written statement of the topic is essential because participants can seem to agree verbally about the topic but usually disagree about what is meant when the verbally expressed topic is committed to paper. This activity in the development of scenarios and associated analyses can be accomplished in several ways.

\subsection{WORKSHOP}

The workshop is one way to reach agreement about the topic that will be the subject of scenarios. The subjects can range from global subjects like trade, politics, energy and economic conditions to very narrow subjects like the future need for research on a particular technology or the effect on various factors judged to be important of specific low probability high consequence events like oil embargoes or significant technological breakthroughs. The workshop is a good setting for reaching agreement about the topic particularly if the subject of the scenarios is going to be used by the individuals who attend the session. Also, the workshop can be used to refine the framework of the analysis so that it can be presented as a candidate topic to the users. The workshop is not a very good method to involve very high level potential users because frequently these people do not have the time to attend a workshop and debate the pros and cons of a topic subject. Also, the attendance of very high level people in a workshop can inhibit the discussion that is necessary to explore all the possible factors before choosing the critical ones for inclusion in the analysis.

\subsection{SURVEY}

Frequently a scenario model for long term forecasting is developed for a large number of potential users who cannot be brought together in a workshop. The administration of a survey instrument (questionnaire) is an excellent way to collect inputs from the potential users. This instrument must ask for a 
statement of the topic, a description of the scope in time, geography and subject, and a listing of the factors that are judged to be critical for a well-rounded analysis of the topic.

This questionnaire can be administered by mail in which case a test of the survey instrument is essential. A telephone survey using the questionnaire to record the information is an alternative method of obtaining the necessary information to define the topic. A one-on-one administration of the questionnaire is also possible. In this case, the person administering the questionnaire should be a participant in the progran to develop the model because frequently nuances in the response will be useful after all responses are collected. Sometimes this can help in establishing the priorities for the selection of the important elements (descriptors) and their respective states.

\subsection{STRUCTURED INTERVIEW}

The structured interview is similar to the one-on-one questionnaire survey instrument. However, because it is a personal interview, the respondent may feel more at ease. Also, the design of the survey instrument does not need to be as carefully developed as for an instrument that is mailed or administered by telephone. The questions to be addressed can be fairly general and can be stated to elicit a broad range of response from the individual. This places a greater premium on having the interviewer be experienced and understand the potential use and application of the information that is collected. The benefit of this approach is that the interview process can be an educational experience for the person who is conducting it and can help insure that the model developed is useful to, and defendable, by the potential users.

\subsection{TOPIC CONTENT}

The critical elements for establishing the topic include the time period, the geographical scope and the technical scope of the analysis. In addition, for the model to be useful, it must contain descriptors that constitute the information to be forecast for the analysis. Seeking the forecasted variables is the most effective method for reaching agreement about what is relevant to the topic. This involves asking the participant or respondent what information about the future is essential to making a useful forecast. Is it interest rates, expenditures on research and development, or timing of the innovation 
of a particular technology? These questions will help establish a scope for the scenarios to be used in the analysis that is narrow enough to be completed given available resources. If the model is to be used for policy analysis, the actionable policy variables must be included in the scope of the analysis. In addition, it is important to include within the scope any other variables that the user normally views as important to the future environment. Including these variables in the analysis may be shown to be unnecessary from a technical perspective but are very important to produce an analysis that the user can accept (because it contains the elements that he or she feels is critical to the full understanding of the future).

The time period of the analysis can vary from a short period of 2 or 3 years to longer periods up to twenty years and possibly more, depending on the topic and the need. As the time period is extended, the factors that are important in forecasting change are different from those that are usually included in standard forecasting models. Longer time periods require the consideration of social, political and technological factors that are not usually incorporated into traditional econometric models very satisfactorily. The DOECIM approach facilitates the inclusion of variables that are more qualitative in nature or for which data are poor or nonexistent.

The geographical scope of the analysis is important to establish in defining the topic because it can help reduce the amount of effort necessary in collecting background data and information. For instance, if economic conditions are important to the forecasts, establishing that the relevant geographical area is the United States rather than the whole world, it will substantially focus the necessary work in collecting the background information.

The technical scope of the analysis will probably be modified as the development of the model progresses. The technical scope will probably change over time because the factors that are important will be different a year after the model is built. They will differ in importance and emphasis. Some factors will disappear and others will emerge as important. Generally, the model should contain factors that relate to the broad categories: social, technological, economic and political. 
* 


\subsection{IDENTIFYING AND PRIORITIZING DESCRIPTORS}

Descriptors are the fundamental building block of scenarlos using the DOECIM approach. The identification of descriptors is a step in the scenarios building process that is common to all formal approaches that are in use today. The step in which the topic is defined serves to establish the scope of the work. The step of identifying and prioritizing descriptors is one in which first the team will seek to identify all possible relevant factors. This usually results in a long list of candidates. The candidate list must be refined and revised during the course of the work to remove redundant and irrelevant factors.

The identification of the list requires the involvement of people who are willing to be creative and offer ideas and concepts without being concerned about whether they seem to make sense in a conventional analysis of the problem area. Also, the environment for identifying these factors must be an open environment in which consideration is given to what the possibilities are and criticism of ideas is minimized. Debate is useful to some extent but generally would be minimized in the part of this step that is involved in identifying a comprehensive list of candidate descriptors. Clarification of the meaning of suggested candidate descriptors is essential for the next part of the step in which the descriptors are prioritized.

The methods for accomplishing this step are the same as those described for defining the topic. However, the workshop environment in which brainstorming and idea generation techniques can be applied is particularly appropriate. These techniques should be undertaken with an experienced facilitator. There are a variety of pin-card and flip-chart approaches.

The prioritization of descriptors is essential to reduce the total number that must be worked with and also to begin consideration of the interrelationships among them. Descriptors that are redundant (the wholesale price index and the consumer price index for instance) and/or that will have approximately the same effect on other descriptors can be eliminated from the list.

The final list of descriptors is used to form the cross-impact matrix. The method of completing this matrix is described in subsequent sections of 4.1 
this report. The interaction among descriptors is critical to the successful development of this matrix. Descriptors affect each other by having the occurrence of one state for a descriptor affecting the probability of occurrence of another descriptor state. If they do not affect each other, the matrix will be empty and the specification of the factors that describe the future for the topic chosen is probably poor.

This bears on the selection of the appropriate descriptors because the value of the cross-impact technique is in the analysis of a large number of interactions that might normally not be considered as possible in developing a model. The simplest way to establish priorities among descriptors is to have the experts who participated in the development of the long list vote for the ones they view as most important. The votes can be weighted according to the level of expertise the voting expert offers. Also, to reduce the bias in the voting, the group that participates in the workshop should be carefully selected to insure an appropriate breadth of expertise covering the major areas (social, political, economic, technological) of concern.

A useful technique to help insure the desired breadth of coverage is to group descriptors into major areas. By inspection, areas that are not covered well will become apparent. This can be used as a cue to identify additional descriptors in the deficient area. Another way to evaluate the array of descriptors is to group them by "arena". One arena might be global, another national, and another a specific organization or technology. Descriptors that are grouped in this way can be evaluated to assess their desirability.

Some descriptor states will be judged to have a very low probability of occurrence. If the probability is judged low and the potential effects are judged high, this descriptor state may be treated as a disruptive event. A separate analysis of the low probability high consequence events can be conducted in the form of a sensitivity analysis. This is an approach that al lows descriptor states that are included in the matrix to be states that have a reasonable probability of occurrence. With DOECIM algorithm, the solutions are very unlikely to contain outcomes for descriptors that initially have very low probabilities of occurrence. Recognition of the fact that a descriptor or its expected state can be introduced later in the analysis permits them to be screened out and set aside for subsequent sensitivity analysis. 


\subsection{DEFINING DESCRIPTORS}

Once the set of descriptors has been chosen that are the highest priority for the topic at hand, these descriptors must be defined and a measure of each descriptor selected. The definition should provide insight into how the descriptor interacts with other descriptors; an historical perspective on how the descriptor behaves over time; and an explanation of the likely variables that will influence the descriptor over the time horizon of the topic. The process of defining the descriptors and the states that these descriptors assume can be done formally or informally. When done formally, the product is an essay on the descriptor, representative samples of which appear as Appendix $C$. However done, the exercise should generate the same set of information that serves as input to the construction of the cross-impact matrix.

The components of that information set are as follows. The descriptor needs to be precisely defined. The reason that the descriptor is important to the topic needs to be explained; a major component of this explanation is how the descriptor interacts with other descriptors. How the descriptor has behaved in the past provides a perspective on the states that the descriptor can assume. A discussion of the current status of the descriptor allows the identification of factors that bear immediately on the trajectory of the descriptor state and provides an introduction to the most critical information required by DOECIM: what are the likely states of the descriptor in the future? A brief description of each of these pieces of information follows.

\subsection{DESCRIPTOR DEFINITION}

When a laundry list of descriptors is first identified and prioritized, groups of descriptors are typicaliy lumped together under one heading. To use an example from the industrial sector study, a measure of the cost of capital is considered important in the adoption of new technology, as are the lost opportunities of not investing and the price of capital goods. Clearly all of these concepts are closely allied and can be grouped together, but what is the common thread that ties these concepts into a single measure that would be useful for an exercise in policy analysis? The common variable among these measures in a rate of interest: it is a major component of the cost of capital goods, it is a direct measure of opportunity costs and it reflects 
the underlying productivity, and hence price, of capital goods. But recognizing that the rate of interest will capture the effect of these influences solves but one of the problems faced in defining the descriptor. Clearly there are many rates of interest.

The interest rate selected for the industrial sector analysis was the prime rate. This rate was chosen for several reasons. It is probably the best single measure of the cost of borrowing from a business perspective. Although this applied only to a bank's best business customers, most other rates are tied to it. The prime rate applies to just that situation that is of concern to the topic at hand: it reflects the costs of investing in new plant and equipment. The prime rate is an interest measure that has been collected over a long period time so that a variety of business conditions can be considered in its movement over time.

The essence of this definition is to select a measurable variable that applies to the topic at hand and captures the important influences that the selection process indicated were of importance. The next step, then, is to articulate how these factors are interrelated.

\subsection{RATIONALIZING THE DESCRIPTOR}

The major purpose of this section is to explain the importance of this descriptor to the topic and to provide some insight in to the way that this descriptor interacts with the other descriptors included in the analysis. The example shown in Appendix $D$ on interest rates has the following outline. The rationale section first explains the importance of this descriptor to the topic. It then describes how the descriptor would influence residential energy consumption directly through affecting the cost of borrowing for appliances and residential retrofits, and indirectly though the influence of the interest rate on general economic activity. In this latter discussion, the essay briefly describes the different ways that interest rates and general economic activity are linked, and references published discussions of alternative theories.

\subsection{HISTORICAL TRENDS}

This section provides some evidence of the historical movements that have occurred in the descriptor. The purpose of this section is to provide some background on the possible states that the descriptor can assume. In 
the example shown in Appendix $D$, a plot of the prime rate, the rate of inflation and the rate of growth of real Gross National Product (GNP) are plotted over the period 1950-1984. Inflation (the change in the Consumer Price Index) is included because of the tie between real returns and the rate of inflation. The growth rate of GNP is also plotted to provide evidence of the countercyclical relationship between interest rates and changes in GNP.

\subsection{CURRENT STATUS}

The current status discussion in the essay provides information on how the status of the descriptor may have changed recently or may change in the

near future. Again using the interest rate essay as an example, this section highlights the change in Federal Reserve Board (Fed) strategy, beginning in October, 1979, of targeting monetary aggregates rather than interest rates. The result of this change in strategy was the increased volatility of interest rates until the Fed modified its strategy in 1982. Another topic of this section of the essay is current: when the essay was written in 1985, the perspective was for continued monetary tightness as a policy to prevent the resurgence of inflation. Subsequently the perspective has changes somewhat, to more monetary ease. Whatever the current status, future prospects are affected by that status since there is considerable inertia in any economic system.

\subsection{FUTURE PROSPECTS}

This section articulates the likely states that the descriptor will take over the time horizon of interest to the problem. These states will be conditioned by what has happened in the past and our perceptions will be influenced by the current status. The product of this segment of the essay should be a set of descriptor states defined and a priori probabilities assigned to each state. A brief discussion of the major uncertainties should also be included to alert the reader to major events that could alter the probabilities.

\subsection{FOLKLORE ON DESCRIPTOR ESSAYS}

Writing formal essays for each of the descriptors is a time consuming task: experience in this activity suggests that a knowledgeable individual might take approximately a week for each of the essays, assuming that they are constructed from scratch. The experience at the Battelle columbus 
Laboratory is that this process can be substantially shortened if an essay is on file that can be used as a starting point. Even if this is the case, some time is required to update the relevant data, tailor the logic to the particular problem, and rationalize the uncertainties surrounding current projections of descriptor states.

In the course of using the industrial sector as an example to exercise the DOECIM software, considerable debate ensued concerning the "best" set of a priori states. At first, there appeared to be some advantage to defining the probabilities so that one state was more likely than the other state(s). Subsequent experience with the software suggests otherwise. At the conclusion of this exercise the consensus of opinion was that the probability states ought to be nearly the same order of magnitude. That is not to argue that the states should remain equiprobable in the conditional probability matrix; if that were true, then virtually no other variable would have any effect on the a priori states, and there would be little reason to include the descriptor in the analysis.

How the probabilities of each of these states changes if another descriptor state occurs is the essence of the construction of the cross-impacts matrix. To this topic we now turn. 


\subsection{DEVELOPING CROSS-IMPACT MATRICES}

The descriptor essays provide a set of a priori probabilities for the states that the descriptors will assume; these provide the starting point for the construction of the cross-impact matrix. The recommended strategy for the construction of the cross-impact matrix is to first select a small team of analysts who begin their assignment by becoming familiar with the descriptor essays. The analysts then meet and agree on either an impact matrix or a conditional probability matrix. An impact matrix is one that converts the prior probabilities to conditional probabilities; if the conditionals are the focus of attention, the impact matrix can be constructed from the priors and the conditionals. When this exercise is completed, the cross-impacts matrix exists in a form that DOECIM can use for calculation of scenario probabilities.

In Section 6.0 , a simple cross-impacts matrix will be constructed to illustrate the process. The example includes three descriptors each with three states, contrived by taking a subset of the descriptors from the industrial sector example presented in Appendix B. In Section 6.1, to follow, the descriptors and their states are defined and prior probabilities for each state are shown. In Section 6.2 the conditional probability matrix is constructed, and discussed. Section 6.3 is a brief discussion of impact matrices and how they are used in DOECIM. The final subsection mentions some of the problems associated with the cross-impacts method and explains how DOECIM has been modified to take some of these into account.

\subsection{EXAMPLE DESCRIPTORS AND STATES}

From the example shown in detail in Appendix B, we have selected three descriptors to provide an example of the construction of a cross-impacts matrix. These descriptors are the world oil price, interest rates, and the composition of the industrial sector. The importance of these variables to industrial energy use and intensity are obvious, but the way they are measured requires some explanation (this would normally be discussed in the descriptor essays).

The world oil price could be measured as the spot market price on one of the major international exchanges, as the contract price to major domestic producers, as an index relative to some base year's price, or in constant dollars per barrel (e.g., in 1980 dollars--based on a spot price). The measure 
chosen in this case is in 1985 dollars, with descriptor states defined as "less than $\$ 20$ per barrel", "between $\$ 20$ and $\$ 30$ dollars per barrel", and "greater than $\$ 30$ per barrel". The interest rate, as mentioned previously, is defined as the prime rate (a composite published regularly by the wall street Journal and the Federal Reserve Board), with descriptor states selected as "less than 6 percent", "between 6 and 9 percent" and "greater than 9 percent". The composition of industry (described in more detail in the essay in Appendix C) is the ratio of the most energy-intensive and energy-consumptive industries to total industrial sector activity. This measure is created by dividing industrial sector gross national product (the sum of agriculture, mining, construction and manufacturing GNP) into the sum of GNP originating in the six most energy-consumptive industries: food processing; pulp and paper; chemicals; petroleum refining; stone, clay and glass products; and primary metals. This ratio has ranged from above 26 percent to below 24 percent with a clear declining trend. Accordingly, the descriptor states for this measure have been defined as greater than 25 percent, 23-25 percent, and less than 23 percent. The descriptors, states, and a priori probabilities are shown below:

\begin{tabular}{|c|c|c|}
\hline DESCRIPTOR & STATES & A PRIORI PROBABILITY \\
\hline \multirow[t]{3}{*}{ World 0il Price } & 1. $\leq \$ 20$ per barrel & .30 \\
\hline & 2. $\$ 20$ to $\$ 30$ per barre 1 & .40 \\
\hline & 3. $>\$ 30$ per barrel & .30 \\
\hline \multirow[t]{3}{*}{ Interest Rates } & 4. Prime $\leq 6$ percent & .30 \\
\hline & 5. 6 to 9 percent & .40 \\
\hline & 6. $>9$ percent & .30 \\
\hline \multirow{3}{*}{$\begin{array}{l}\text { Composition of } \\
\text { Industry Sector }\end{array}$} & 7. Ratio $\leq 23$ percent & .30 \\
\hline & 8. 23 to 25 percent & .45 \\
\hline & 9. >25 percent & .25 \\
\hline
\end{tabular}

The states have been identified with a number (1 through 9) so that they can easily be identified when the cross-impact matrix is constructed. Note that the prior probabilities have been specified to be roughly the same magnitude and that the sum of the prior probabilities for each descriptor sum to unity. Thus the likelihood that one of the states of each descriptor will occur is identically one. 


\subsection{BUILDING THE CROSS-IMPACTS MATRIX}

The fundamental question that the analyst asks when constructing the conditional probability matrix is this: If a particular state of one descriptor occurs, how will that effect the probability for the states of other descriptors? Restated in terms of our example, we ask how the prior probabilities for interest rates and industry composition will be changed if oil prices in 1995 are less than $\$ 20$ (between $\$ 20$ and $\$ 30$, greater than $\$ 30$ ) per barrel? In other words, if oil prices are low, will the probability that interest rates are low decline, increase, or remain the same? Operationally, this requires constructing a matrix with a row and a column for each of the states, then proceeding down the column as if that state had occurred, and adjusting the prior probabilities of each of the other descriptor states. If the column descriptor has no impact on the row descriptor, the prior probabilities are simply repeated. If the column state increases the row probability for another state, then the probability of other states of that descriptor must be adjusted to sur to one, just as the prior probabilities sum to one. For simplicity in our example, we will assume that the price of oil has only an indirect effect on interest rates, and that nothing affects the probability of oil price states. Moreover, the composition of industry does not influence the other descriptors. Under these assumptions, the cross-impact matrix might be as follows:

\begin{tabular}{|c|c|c|c|c|c|c|c|c|c|c|}
\hline States & A Priori & $\begin{array}{l}\mathrm{Co} \\
1\end{array}$ & $\begin{array}{r}\text { dit } \\
2 \\
\end{array}$ & $\begin{array}{c}\text { iona } \\
3 \\
\end{array}$ & 4 & $\begin{array}{c}\text { bat } \\
5\end{array}$ & ilit & $\begin{array}{l}C \\
7\end{array}$ & $\begin{array}{r}\text { um } \\
8 \\
\end{array}$ & 9 \\
\hline 1 & 30 & 30 & 0 & 0 & 30 & 30 & 30 & 30 & 30 & 30 \\
\hline 2 & 40 & 0 & 40 & 0 & 40 & 40 & 40 & 40 & 40 & 40 \\
\hline 3 & 30 & 0 & 0 & 30 & 30 & 30 & 30 & 30 & 30 & 30 \\
\hline 4 & 30 & 50 & 20 & 20 & 30 & 0 & 0 & 30 & 30 & 30 \\
\hline 5 & 40 & 30 & 60 & 30 & 0 & 40 & 0 & 40 & 40 & 40 \\
\hline 6 & 30 & 20 & 20 & 50 & 0 & 0 & 30 & 30 & 30 & 30 \\
\hline 7 & 30 & 11 & 21 & 70 & 21 & 22 & 50 & 30 & 0 & 0 \\
\hline 8 & 45 & 22 & 53 & 22 & 34 & 60 & 33 & 0 & 45 & 0 \\
\hline 9 & 25 & 67 & 29 & 9 & 44 & 18 & 17 & 0 & 0 & 25 \\
\hline
\end{tabular}

This matrix can be interpreted as follows. If oil prices are low in 1995 (state one occurs) the probability that interest rates would be low (state 4) increases from 30 percent to 50 percent. Although oil prices may have no direct bearing on interest rates, the probability of low interest rates will increase because ofl prices effect inflation and interest rates and inflation are closely tied together. Accordingly, the probability that alternative 
interest rate states would occur is moderately decreased, so that the sum of rows 4,5 and 6 equals to 100 (note that the probabilities are stated as fractions of 100 . If oil prices are low, we would also expect that the probability that the ratio of energy-intensive industry to total industrial sector output would increase--there would be a halt in the decline of those basic industries and a likely increase in their relative importance. The logic that applies to the first column would apply, in similar fashion, to the next five columns. Where conflicts arise among analysts about that logic, those conflicts must be resolved. This topic will be addressed directly in a later subsection.

This discussion highlights a number of items that need to be made explicit about the structure of the cross-impacts matrix. Note that the first three rows of the first three columns have zero elements except along the diagonal, which replicates the prior probabilities. This is true for the subportion of the cross-impact matrix allocated to a single descriptor. Note also that when one descriptor has no effect on another $(\mathrm{e} . \mathrm{g}$. , the first six rows of columns 7-9), the priors are simply replicated in each column. Finally, we repeat, in all columns where one descriptor is conditioning other descriptors (as opposed to itself), the sum of the probabilities of states of a single descriptor sum to one (hundred).

Once the analysts have constructed the conditional probability matrix, it may occur that their thinking about the prior probabilities changes. This will alter all the conditional probabilities in those rows where the prior has changed. It is not necessary that the matrix be reconstructed, however, because the new conditionals can be calculated using impact scales.

\subsection{THE IMPACT SCALE MATRIX}

Rather than construct a conditional probability matrix, one could define an arbitrary scale, say from -3 to +3 , indicating the effect on the prior probability that the occurrence of a state would have. That is, if low oil prices occur in 1995, would that have a strong positive effect $(i . e,++3)$, a moderate effect $(+1$ or +2$)$, no effect $(0)$, or a negative effect $(-1$ to -3$)$ on the probability that interest rates would be low? These impact scales could be identified for each cell of the cross-impact matrix and used to modify the prior probability, thereby constructing the conditional probability matrix. 
The strategy followed in DOECIM is the reverse of that suggested above. The conditional probability matrix is filled in, then the impact matrix is calculated based on the conditionals and the priors. This impact matrix is then stored in the event that the priors are changed. The option also exists for the impact scales to be entered first, then used to construct a conditional probability matrix. In DOECIM, the arbitrary scaling is from -30 to +30 . In Appendix $B$ the impact matrix associated with the conditional probability reported for the 10-descriptor industrial sector case is reported. When the conditional probabilities are entered, rather than the impact scales, it is possible that the calculated impact matrix can have values greater than $|30|$. In Appendix B, the impact matrix reports numbers greater than 30 .

\subsection{PROBLEMS THAT APPLY TO CROSS-IMPACT ANALYSIS}

There are several difficulties associated with applying cross-impacts analysis to any problem. One problem arises when more than one individual constructs the matrix. Invariably there is disagreement about the logic of cause and effect. Some of these disagreements can be resolved by keeping in mind that the conditional probability matrix simply asks how the probability of one event is influenced by the occurrence of another event. If there is continuing disagreement, one method of resolution is to have the proponents articulate the reasoning, then to reach some consensus among the majority of the analysts. To speed this process up, it helps to keep a diary of the major disagreements, so that the alternative reasoning can be used as a basis for sensitivity analysis later.

There are two major methodological problems with cross-impact analysis, apart from the computational problems (discussed in Section 7.0). The first is the deficiency that arises as a result of employing only first order conditional probabilities (i.e., an event having an effect on another variable with no recognition that several events may jointly interact on a variable) in a world where joint conditionals are the rule, not the exception. The second relates to the way that non-included variables of importance are excluded from having a first order effect. The state-of-the-art in cross-impact analysis provides no solution to the first problem; but for the second problems there is a modest solution. 
The problems of having important excluded variables having an influence can be solved by building the conditional probability matrix to channel these effects through the included variables. The rule of thumb that our experience suggests works is this: if a descriptor influences another variable directly, then that effect is recorded through a change in the prior probability, in accordance with the strategy outlined previously. If a descriptor influences another variable indirectly, then two cases are identified: if descriptor $A$ is influenced by variable $B$ indirectly because variable $C$ affects $B$, then the indirect effect of $C$ on $A$ through $B$ is ignored if the effects of $C$ are captured directly by an included descriptor; the effects of $C$ on $A$ are included through $B$ if no other descriptor "better" takes into account the influence of $C$.

Clearly the determination of whether $B$ (as opposed to descriptor $D, E$, or $F)$ best captures the effect of $C$ on $A$ is a judgement call. Again, the consensus method of resolving disputes must come into play. If there are strongly held impressions to the contrary, the information should be stored so that sensitivity tests can be conducted as a part of the simulation exercise. 


\subsection{COMPUTATIONAL OVERVIEW}

In the sample problem shown in Section 6.2, there are three descriptors each with three states. In calculating the probability of a set of three different descriptor states occurring at once (which will be referred to as a "scenario"), there can be three possible states for each of three descriptor, or $3 \times 3 \times 3=27$ alternative scenarios. Generally in a DOECIM simulation, there will be $\Pi_{j=1}^{\delta} \sigma_{i}$, where $\sigma$ is the number of states for a given descriptor, $\delta$ is the number of descriptors used to characterize the problem, and the operator II multiplies each of the descriptor states. In the 10-descriptor problem shown in Appendix $B$, there are $3^{10}$ or 59,049 possible scenarios, since each descriptor has three states. As the number of descriptors increases, the number of scenarios increases exponentially. But unfortunately, this is only part of the problem.

In the three variable problem shown above, consider the calculation of the probability of the scenario where states 3,6 and 9 occur [which will be indicated by $S(3,6,9)]$. To calculate the probability of this scenario, we can begin with the a priori probability of any of the three states. Having selected one of these, we then multiply that probability by the conditional probability of one of the other states (of which two remain), then we multiply that product by the remaining conditional probability. So there are three ways to choose the first probability, two ways to choose the second and one way to choose the final probability; i.e., there are three factorial $(3 !=6)$ ways to calculate the probability for each scenario. And in general, there will be $\delta$ ! ways to calculate each scenario. In the three variable case, then, there are 162 possible paths $\left(3 ! \times 3^{3}\right)$ for calculating the probability of all the 27 scenarios. In the 10 -variable case shown in Appendix $B$, there are $10 ! \times 3^{10}=3,628,800 \times 59,049 \approx 214$ billion alternative paths for all the scenarios. Since each of these paths requires nine multiplications, an exhaustive solution for this problem would require nearly two trillion calculations. The addition of a single descriptor to the problem of Appendix $B$ would increase the number of calculations to more than 70 trillion calculations. At a speed of one million calculations per second (a fast IBM PC-AT can perform about 100,000 calculations per second), an 11-descriptor 
problem would require nearly three months to solve. Clearly an exhaustive search is out of the question.

The alternative to an exhaustive search is to design an algorithm that reduces the search space to make the problem more manageable. In the course of this project a number of alternatives have been examined, applied to small problems, then rejected. The solution algorithm that has been selected is referred to as the "Lamp Post" algorithm, and relies on a sensible (though not perfect) reduction of the search space to manageable size (see Appendix 0 ).

The strategy of Lamp Post can be explained by reference to the three descriptor problem of Section 6.2. Envision that conditional probability matrix in three dimensions: at the base are the two dimensions indicated by the set of possible states; the third dimension would show the probabilities as elevated bars, their height scaled to the size of the probability. Now consider lowering, incrementally, a plane from above the highest probability until several of the bars poke above the plane. The plane we refer to as a threshold. The essence of the Lamp Post algorithm is to lower the threshold to a specified level, then search the space to see if enough probability posts stick through the plane to define a scenario. If not, the threshold is lowered until a set number of scenarios can be identified. Once these are identified, a random sample of paths for each scenario is selected and the probabilities over that sample are calculated and averaged to yield an estimate of the true probability for that scenario.

A more detailed description of the Lamp Post algorithm is provided in Appendix D. 


\subsection{ANALYZING SIMULATION RESULTS}

The analysis of simulations produced using the DOECIM algorithm can range from inspection of the matrix to sensitivity analyses after changing underlying judgments.

\subsection{MATRIX}

Before any simulations are attempted and after the matrix has been filled out, the matrix can be examined to identify areas where changes in a priori probabilities are small and areas where the changes are large. Examination of the relative strength of the impacts demonstrates in a general sense, the implicit relationships that the people making the judgments are anticipating. This concept can be used to indicate, before filling out the matrix, which descriptors are thought to have a strong relationship and which a weak or no relationship. The pattern of the relationship can also be examined to insure that outcomes that increase the probability of another state are offset by alternative outcomes that decrease the probability. As long as the descriptor states represent a continuum of possible outcomes, there should be a regular pattern to the impact values or the changes in the conditional probabilities.

\subsection{DRIVER AND DRIVEN DESCRIPTOR STATES}

The printout of the matrix, using DOECIM, will show a column and row called non-zero entries. This is the number of times a non-zero entry appears in the subject row or column of an impact matrix. A row that has a large number of non-zero entries represents a descriptor state (in the left hand column of the matrix) with an a priori probability that is affected by the occurrence of a large number of other descriptor states. This could be referred to as a driven descriptor. This means also that there would be only a few zero entries in the row--almost all other states affect the subject descriptor state. If the number of non-zero entries is very small or zero, that indicates that the row descriptor state is not affected or driven by changes in other descriptor states in the matrix. So the driven descriptor state is on that has a row in which there are a large number of changes in the a priori probability indicated. Extending the analysis to descriptors, the sum of the non-zero entries is an indicator of how much a descriptor is affected by changes in other descriptors. However, because this means that descriptors

8.1 
with many states could experience more changes than those with few states, the calculation of an estimate of the extent to which a descriptor is affected is to add all the non-zero entries and divide by the number of states. This gives an average number of non-zero entries for a given descriptor.

Using this same approach, the extent to which a descriptor is a driver is determined. The non-zero entries for a given column are added to estimate the extent to which the occurrence of a descriptor state affects the a priori probabilities of other descriptors. If this value is large for a descriptor or descriptor state, it is referred to as a driver. Lower values or zero values for a column indicate descriptors or states that do not drive other descriptors. DOECIM will calculate non-zero entries, divide by the relevant number of states and report the results in a table listing all descriptors and the average number of non-zero entries.

\subsection{BASE-CASE}

After examining descriptors, the matrix, and drivers and driven descriptors, DOECIM will simulate and report the top ten outcomes. These outcomes represent the ten most likely possible combinations of descriptor states. Subsequent simulations after having made changes in the underlying judgments can be compared to the base-case to determine what the effect of changes in judgement would be.

The outcome with the highest probability of occurrence is listed first. The joint probability is calculated to indicate the probability that the states selected will occur. The joint probability for a single outcome is usually very small. As a result, a scaling factor is applied to the probability estimate so it can be reported and printed out in the space given. For each outcome, the minimum and maximum probability is also calculated. This gives the analyst an indication of the range of possible probabilities that could occur for a given set of results. The variation occurs because, for any set of results, the order in which the joint probability is calculated will affect the final value.

Also, for each outcome a standardized probability is calculated. This is a hypothetical value that is derived by adding the joint probabilities for 
the top ten outcomes and normalizing them to add to one. This allows a rapid comparison of the relative size of the probabilities in the top ten.

\subsection{SENSITIVITY ANALYSIS}

There are a variety of simulations that can be made and compared to the base-case. The comparisons may show that a low ranked possible outcome is increased in likelihood or that a high ranked outcome is decreased in likelihood. In some cases changes might be expected to significantly alter the likelihood of a dominant outcome but upon analysis, it does not. In such a case, the analyst must ask if the model is specified correctly. If so, the expected effect is not likely to be as great as originally anticipated.

\subsubsection{Impact Values}

One type of simulation is to change the impact values or conditional probability entries in the cross-impact matrix. The entries in the matrix are based on Judgement and are subject to alternative interpretations which could lead to alternative values. Analysis of the major alternatives can be undertaken by entering the alternative values in the matrix, executing the simulations and comparing the results. If the judgments are substantially different and the effect of the differences is also great, this is a signal that more effort to reconcile the differing judgments might produce a more reliable or defensible result.

\subsubsection{A Priori Probabilities}

The a priori probabilities are established at the outset of the analysis and because they too are based on expert judgement, are subject to possible differences. The voting process, however reported and reconciled, will frequently result in outlier opinions being reconciled to reach consensus. In some cases the outlier opinion may not be changed after debate. The rationale for the judgement may be unaffected by the arguments presented. In this case, analysis using the alternative a priori probability will indicate how great a difference the alternative will make in the final analysis. If the difference is great, reconciliation of opinion should probably be undertaken.

In many cases the differences of opinion can be reconciled by considering a broader scope for the analysis. This might mean the addition of some

$$
8.3
$$


intermediate descriptors to the analytical framework or it might entail the consideration of a time period that is different from the one established originally for the analysis. In any event, either the differences can be reconciled or the results using both of the alternative judgments are used in the analysis, indicating the range of uncertainly that underlies the forecasted scenario.

\subsubsection{Low Probability, High Consequence Events}

Another type of simulation adds, then preselects, a new descriptor state that would not normally be included. These descriptor states are imposed to determine what effect a low probability event might have on the outcome of the calculated scenarios. These low probability events are included because their potential effect on the environment would significantly alter the state of the world. For example, a major war in the Middle East could significantiy alter the world price of oil and would have dramatic consequences for industrial energy use and consumption.

\subsubsection{Descriptor States}

In choosing the relevant descriptors considerable judgement is exercised. This judgement is also subject to debate and the specification of the most relevant descriptors is not always certain. As a result, the addition or deletion of descriptors is a commonly undertaken simulation. This involves adding or subtracting rows and columns in the cross-impact matrix. DOECIM makes this convenient and new results can be obtained with the changed descriptors in the matrix. The new results can be compared to prior results to determine how the changed descriptor affects the outcome or the likelihood of the outcome.

The definition of descriptor states also involves judgement. The states must be mutualiy exclusive and exhaustive. They also must be specified in such a way as to be relevant to the user of the results of the work. Outcomes must be expressed in discrete ranges over the set of all possible outcomes for the descriptor. The specification of the range for each state can also affect the a priori probability of occurrence of that outcome. If a possible outcome is that, for instance, GNP will fall in the range of 2 to 4 percent real growth per annum, it is likely to have a much greater a priori probability 
than if the outcome were that GNP would grow at 2 to 2.5 percent per annum. Adjustment in the range of possible outcomes is another type of analysis that can be conducted.

8.5 
$\cdot$
$\cdot$
$*$
"

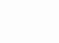




\subsection{INTERPRETING RESULTS}

The results of the simulations can be used as the framework for scenarios of the future. This is the most conmon application. To the extent that forecasted variables are included in the descriptor set and the outcomes for the forecasted variables range widely enough to provide useful outcomes, the scenarios can be reported directly. Usually these scenarios are reported in written form rather than as computer printouts. This means that the analyst must be able to describe why and how the specific results occurred and why al ternatives did not occur. Reference to the printouts, the matrices, the a priori probabilities, and the details of any particular simulation will help in this interpretation.

\subsection{WORKSHOPS}

One method of gaining greater interpretation from the results is to use them as the basis for an implications workshop. This workshop would be conducted to present the results of the analysis, identify key factors that could affect the future that is relevant and evaluate how the future would be affected by the outcomes that were derived from the analysis. For instance, an important factor might be the likelihood of a technological breakthrough. The potential for such a technological breakthrough will probably change under alternative scenarios. An examination of the alternative scenarios and discussion of the implication for the breakthrough could yield insight regarding the likelihood of the breakthrough under alternative sets of conditions. Knowing the probability or relative probability of the alternative scenarios will give insight regarding the probability or relative probability of the technological breakthrough.

The advantages of the workshop lasting four to eight hours, are twofold: format the discussion of the results and their implications is disseminated to a large group; and much of the benefit of the work is delivered in a common setting. To have the same group read a report containing the scenarios and examine the implications individually will not produce the same level of effort or the same level of understanding. The major disadvantage of the workshop is that a great level of depth is difficult unless the participants have been actively involved in the program up to that time. 


\subsection{FORECASTS}

In some cases, detailed forecasts of a highly quantitative nature are useful to the user. DOECIM is not a tool that will produce detailed quantitative forecasts. However, if there is an econometric (or other) model that can be used to produce detailed quantitative forecasts, the exogenous variables may be drawn from the results produced using DOECIM. For this to be successful, the exogenous variables must be specified as descriptor states or directly relatable to descriptor states in DOECIM. This means the need for them must be anticipated and they must be included in the set of descriptors chosen for the matrix. Producing detailed quantitative forecasts in support of the more general scenarios will frequently assist the recipient in interpreting the results for their own use. 


\subsection{CONCLUSIONS}

Cross-impact analysis is a relatively new approach to the art of developing and analyzing future scenarios. Since its introduction in 1968, cross-impact analysis has received considerable attention in the literature as evidenced by the nine-page bibliography in Appendix $A$ that contains over 100 entries. The state-of-the-art in cross-impact analysis is not fixed but is in a state of flux. It has undergone considerable modification since its introduction, and is still the subject of much experimentation and revision. Most cross-impact analysts argue that much more development is not only possible but needed before the methodology can lay any strong claim to rigor.

As a policy analysis and forecasting tool, cross-impact has its place alongside econometrics, trend analysis, systems dynamics, DELPHI and other approaches and techniques. Cross-impact analysis appears best suited to problems that are broad in scope, deal with a subject that is expected to undergo considerable change over the forecast period, deal with variables that are difficult to quantify, and address policy issues where uncertainty over future outcomes and events is of considerable concern.

The computer software that has been developed called DOECIM (for DOE Cross-Impact mode1), operates on our IBM-PC or compatible microcomputer with at least $348 \mathrm{~K}$ of memory and two disk drives. The software is menu driven and employs full prompting at all times for ease of use. The software includes an instruction guide and three program diskettes. DOECIM has been designed to follow more closely the theory of joint probability estimation than do other scenario generation procedures.

The first two steps in cross-impact analysis, topic definition and descriptor identification, are best accomplished in workshop settings attended by eight or less participants who are experts in various aspects of the energy issue: technology, institutions, economics, human behavior, etc. These workshops should be highly structured meetings led by a facilitator to keep the meeting on track and ensure that all individual participate. These sessions are labor intensive so participants should be prepared to make a commitment to spend the necessary time. 
The state-of-the-art in cross-impact analysis is not fixed but is in a state of flux and much more development is not only possible but needed before the methodology can lay any strong claim to rigor. DOECIM has advanced the state-of-the-art in several important respects. For one, the computational algorithm that produces most likely scenarios is based on conditional probabilities of joint events, unlike other scenario development techniques. In addition, analysts have considerable flexibility in structuring the process and using the software to address analytical needs. The six-step process provides a useful structure for many analytical inquiries even if the analyst does not intend to develop future scenarios or use the DOECIM software. Similarly, the experienced analyst could forego the six-step process and work directly with the software if scenario analysis is needed under short deadlines. 
APPENDIX A:

CROSS-IMPACT AND TECHNOLOGY

ASSESSMENT BIBLIOGRAPHY 
Allen, T. Harrell. 1978. "Cross-Impact Analysis: A Technique for Managing Interdisciplinary Research," SRA Journal, pp. 11-18.

Alter, Steven. 1979. "The Evaluation of Generic Cross-Impact Models, " Futures, pp. $132-150$.

Amara, Roy C. 1972. "A Note on Cross-Impact Analysis: A Calculus for Sequence-Dependent Events," Futures, pp. 267-271.

Angrist, Shirley S., Jacob Belkin, and William A. Wallace. 1976. "Social Indicators and Urban Policy Analysis," Socio-Economic Planning Sciences, Volume 10, No. 5, pp. 193-198.

Arthur D. Little. 1981. The Strategic Management of Technology.

Beasley, J.E., and R. Johnson. 1984. "Forecasting Environmental Protection Legislation Using Cross-Impact Analysis," Long-Range Planning, Volume 17, No. 6, pp. 226-228.

Beasley, J.E., and R. Johnson. 1983. "Some Cross-Impact Refinements," Futures, pp. 226-228.

Becker, Harold S. 1983. "Scenarios. A Tool of Growing Importance to Policy Analysis in Government and Industry, "Technological Forecasting and Social Changes, Volume 23, pp. 95-120.

Bitondo, Domenic, and Alan Frohman. 1981. "Linking Technological and Business Planning, " Research Management, pp. 19-23.

Blackman, A. Wade, Jr. 1973. "A Cross-Impact Forecasting for Long-Range Planning," Technological Forecasting and Social Change, Volume 5, pp. 233242.

Bloom, Mitche1 F. 1975. "Deterministic Trend Cross-Impact Forecasting," Technological Forecasting and Socjal Change, Volume 5, pp. 35-74.

Bloom, Mitchel F. 1977. "Time-Dependent Event Cross-Impact Analysis: Results from a New Model," Technological forecasting and Social Change, Volume 10, pp. 181-201.

Bonnickson, Thomas M. 1981. "Brushland Fire-Management Policies - A CrossImpact Simulation of Southern California, "Environmental Management, Volume 5, No. 6, pp. 521-529.

Booz, Allen \& Hamilton, Inc. Strategic Management of Technology: The Role of Technology Investment in Developing and Maintaining Competitive Advantage, vugrahps.

Chatel, Bertrand H. 1979. "Technology Assessment and Developing Countries," Iechnological Forecasting and Social Change, Volume 13, pp. 203-211. 
Chen, Kan, Kenan Jarboe, and Janet Wolfe. 1981. "Long-Range Scenario Construction for Technology Assessment," Technological Forecasting and Social Change, Volume 20, pp. 27-40.

Christakis, Alexander N., et al. 1979. "Forecasting Science and Industry: Science Forum Approach," Technological Forecasting and Social Change, Volume 13, pp. 107-129.

Clapham, W. B., Jr., R. F. Pestel, and H. Arnaszus. "On the Scenario Approach to Simulation Modeling for Complex Policy Assessment and Design, "Policy Sciences, Volume, pp. 157-177.

Coate, Malcolm B. 1983. "Pitfalls in Portfolto Planning," Long-Range Planning, Volume 16, No. 3, pp. 47-56.

Coates, Joseph F. 1976. "The Role of Formal Models in Technology Assessments," Technological Forecasting and Social Change, Volume 9, pp. 139-190.

Coates, Joseph F. 1977. "Technological Change and Future Growth: Issues and Opportunities," Part One, Technological Forecasting and Social Change, volume 11, pp. 49-74.

Cole, Sam. 1976. "Long-Term Forecasting Methods: Emphasis and Institutions," Futures, pp. 3-20.

Collazo Rivera, Carmen A. 1982. A Simulation of Employment Policies' Impact in the Florida State University System Using Delphi and Cross-Impact Techniques, Dissertation submitted to Department of Educational Leadership, The Florida State University.

Coplin, William D., and Michael K. O'Leary. 1984. "The 1984 Risk Index for International Business," Planning Review, pp. 34-40.

Covello, Vincent T. 1983. "The Perception of Technological Risks: A Literature Review," Technological Forecasting and Social Change, Volume 23, pp. 285-297.

Dajani, Jarir S., and Gorman Gilbert. 1975. "Delphic Predictions and Cross Impact Simulation," Journal of the Urban Planning and Development, pp. 49-59.

Dalkey, Norman C. 1971. An Elementary Cross-Impact Model, report prepared for Advanced Research Projects Agency, R-677-ARPA.

Dalkey, Norman C. 1972. "An Elementary Cross-Impact Model," Technological Forecasting and Social Change, Volume 3, pp. 341-351.

Dede, Christopher, and Dwight Allen. 1981. "Education in the 21st Century: Scenarios as a Tool for Strategic Planning," Phi Delta Kappan, January pp. 362-366. 
Dickey, John W., et al. 1981. IIP: The Trends Integrator Procedure, Monograph Series on Strategic Planning by the College of Architecture and Urban Systems, Division of Environmental and Urban Systems, Virginia Polytechnic Institute and State University, Blacksburg, VA.

Ducos, Gilbert F. 1980. "Two Complementary Cross-Impact Models: MIP 1 and $\mathrm{MIP}_{2}, "$ Futures, pp. 405-419.

Ducot, C. 1980. "Futures Research Scenarios and Time Succession," Technological Forecasting and Social Change, Volume 17, pp. 51-59.

Duval, A., E. Fontela, and A. Gabus, 1975. "Cross-Impact Analysis: A Handbook on Concepts and Applications," in Maynard M. Baldwin, editor, Portrajts of Complexity. Applications of Systems Methodologies to Social Problems, Battelle Memorial Institute, Columbus, OH, pp. 202-222.

Enzer, Selwyn, and Steven Alter. 197B. "Cross-Impact Analysis and Classical Probability," Futures, pp. 227-239.

Enzer, Selwyn. 1972. "Cross-Impact Techniques in Technology Assessment," Futures, pp. 30-51.

Enzer, Selwyn. 1970. "Delphi and Cross-Impact Techniques: An Effective Combination for Systematic Futures Analysis," in Proceedings of the International Future Research Conference, Kyoto, Kodansha Ltd., Tokyo, Japan, pp. 17-37.

Enzer, Selwyn. 1979. An Interactive Cross-Impact Scenario Generator for Long-Range Forecasting, Ph.D. dissertation, University of Southern California.

Enzer, Selwyn. 1980. "INTERAX--An Interactive Model for Studying Future Business Environments: Part I," Technological Forecasting and Social Change, Volume 17, pp. 141-159.

Enzer, Selwyn. 1980. "INTERAX--An Interactive Model for Studying Future Business Environments: Part II," Technological Forecasting and Social Change, Volume 17, pp. 211-242.

Foel1, Wesley K., and Mark E. Hanson. 1980. "Futurists and State Energy Policy: The Wisconsin Story," Technological Forecasting and Social change, Volume 1B, pp. 341-358.

Fontela, Emilio. 1976, "Industrial Applications of Cross-Impact Analysis," Long-Range Planning, pp. 29-33.

Foster, Richard N. 1984. "A Call for Vision in Managing Technology," Business Week, pp. 24, 26, 28, 33.

Gershuny, J. 1976. "The Choice of Scenarios," Futures, pp. 496-508. 
Godet, Michel. 1976. "Scenarios of Air Transport Development to 1990 by SMIC 74--A New Cross-Impact Method," Technological Forecasting and Social Change, Volume 9, pp. 279-288.

Goldman, Rita Pauletter. 1981. A Cross-Impact Matrix Examining Possible Future Effects of Career Education on Private Liberal Arts Institutions, Dissertation submitted to School of Education and Human Development, The George Washington University.

Gup, Benton E., and David D. Whitehead. 1983. "Shifting the Game Plan: Strategic Planning in Financial Institutions," Economic Review, pp. 279-88.

Hamilton, H. Ronald. 1980. "Scenarios in Corporate Planning," Economics and Policy Analysis Occasional Paper No. 14, Battelle's Columbus Division, Columbus, $\mathrm{OH}$.

Harman, Willis W. 1975. "On Normative Futures Research," Policy Sciences, Volume $6, \mathrm{pp} .121-135$.

Harris, John M., et al. 1983. "The Strategic Managenent of Technology," Planning Review, pp. 28-35.

Helmer, 0laf. 1972. "Cross-Impact Gaming," Futures, pp. 149-167.

Helmer, 0laf. 1977. "Delphi and Causal Cross-Impact Analysis," Futures, pp. 17-31.

Helmer, 0laf. 1981. "Reassessment of Cross-Impact Analysis, " Futures, pp. 389-400.

Hise, Richard, and Stephen McDaniel. "CEO's Views on Strategy: A Survey," The Journal of Business Strategy, pp. 79-86.

Hoch, Standley H. 1981. "Integrating Social, Economic, Political and Technical Forecasts into Business Strategy," Research Management, pp. 8-12.

Holliday, Darryl R., and Howard E. Lowitt. 1984. "An Integer-Based Blackman Innovation Index: Hypothesis, Evidence, and Implications," Technological Forecasting and Social Change, Volume 26, pp. 58-79.

Hurter, Arthur P., and Albert H. Rubenstein. 1978. "Market Penetration by New Innovations: The Technological Literature," Technological Forecasting and Social Change, Volume 11, pp. 197-221.

Hussey, D. E. 1984, "Strategic Management: Lessons from Success and Failure," Long-Range Planning, Volume 17, No. 1, pp. 43-53.

Ishikawa, M., M. Toda, S. Mori, and Y. Kaya. 1980. "An Application of the Extended Cross-Impact Method to Generating Scenarios of Social Change in Japan," Technological Forecasting and Social Change, Volume 18, pp. 217-233. 
Jantsch, Erich. 1970. "From Forecasting and Planning to Policy Sciences," Policy Sciences, Volume 1, pp. 31-47.

Jensen, Robert E. 1981. "Balancing Laws for R-Space in Cross-Impact Models," Futures, pp. 217-220.

Jensen, Robert E. 1983. Review of Forecasts: Scaling and Analysis of Expert Judgments Regarding Cross-Impacts of Assumptions on Business Forecasts and Accounting Measures, Studies in Accounting Research \#19.

Jones, Laura R. 1983. A Compilation of Published Scenarios and Forecasts.

Jones, Martin V. 1973. A Comparative State-of-the-Art Review of Selected U.S. Technology Assessment Studies, Mitre Corporation, prepared for National Science Foundation, Report No. M73-62.

Kahn, Herman, and Anthony J. Wiener. 1967. The Year 2000. A Framework for Speculation on the Next Thirty-Three Years, Macmilian, New York.

Kane, Julius, Ilan Vertinsky, and William Thomson. 1973. "KSIM: A Methodology for Interactive Resource Policy Simulation," Water Resources Research, Volume 9. No. 1.

Kawamura, Kazuniko. 1979. Prospectus on Conducting Issue-Focused Workshops as an Aid to Policy and Program Planning, Battelle-Columbus Division.

Kawamura, Kazuniko. 1976. Report on KSIM: A Methodology for Interactive Resource Policy Simulation, Battelle-Columbus Division.

Kaya, Y., M. Ishikawa, and S. Mori. 1979. "A Revised Cross-Impact Method and Its Application to the Forecast of Urban Transportation Technology," Technological Forecasting and Social Change, Volume 14, pp. 243-257.

Kelly, P. 1976. "Further Comments on Cross-Impact Analysis," Futures, pp. 243-257.

Kenda11, J. 1976. "A Cross Impact Approach to the Analysis of Pressures on an R\&D Laboratory--Applied to the Case STudy of McCosh and Keeztenbaum, "R\&D Management, Volume 8, No. 2, pp. 75-77.

Klein, Harold E., and Robert E. Linneman. 1984. "Environmental Assessment: An International Study of Corporate Practice," The Journal of Business Strategy, Volume 5, No. 1, pp. 66-75.

Krannich, Richard S. 1979. "A Comparative Analysis of Factors Influencing the Socioeconomic Impacts of Electric Generating Facilities," Socio-Economic Planning Sciences, volume 13, No. 1, pp. 41-46.

Leitch, Jay A. 1983. Natural Resource Issue Identification, Final Report to U.S. Geological Survey. 
Letters to the Editor. 1977. "Scenario Generation by Cross-Impact Analysis," Futures, pp. 87-89.

Levy, David M., and Nestor E. Terleckyj. 1983. "Effects of Government R\&D on Private R\&D Investment and Productivity: A Macroeconomic Analysis," The Bell Journal of Economics, pp. 551-561.

Linneman, Robert E. 1983. "The Use of Multiple Scenarios by U.S. Industrial Companies: A Comparison Study, 1977-1982," Long Range Planning, Volume 16 No. 6, pp. 94-101.

Linstone, Harold A., and Murray Turoff. 1975. "Cross-Impact Analysis," Section $V$ in The Delphi Method. Techniques and Applications, AddisonWesley, Reading, MA.

Linstone, Harold A., and Murray Turoff, editors. 1975. The Delphi Method. Techniques and Applications, Addison-Wesley, Reading, MA.

Linstone, Harold A., et al. 1981. "The Multiple Perspective Concept: With Applications to Technology Assessment and Other Decision Areas," Technological Forecasting and Social Change, Volume 20, pp. 275-325.

Lipinski, Hubert, and John Tydeman. 1979. "Cross-Impact Analysis: Extended SKIM," Futures, pp. 151-154.

Liu, Ben-Chieh, Neils Christiansen, and John Jaksch. 1980. "Measurement of the Socioeconomic Impact of Lake Restoration: An Assessment Model Employing a Benefit/Cost Cross-Impact Probabilistic Approach," American Journal of Economics and Sociology, Volume 39, No. 3, pp. 227-236.

Martino, Joseph P., and Kuei-Lin Chen. 1978. "Cluster Analysis of Cross-Impact Model Scenarios," Technological Forecasting and Social Change, volume 12, pp. 61-71.

McAdams, H. T. March 1985. "Of Cats, Clover, Bees and BASICS: A Position Paper on Cross-Impact Analysis and Related Disciplines," Profit Report to Pacific Northwest Laboratory, Richland, Washington, under Subcontract No. B-M7160-A-Z.

McAdams, H. T. September 1985. "MACS: An Alternative to BASICS: A Working Paper Presenting a Simplified Approach to Cross-Impact Analysis," Draft Report to Pacific Northwest Laboratory, Richland, Washington, under Subcontract No. B-M7160-A-Z.

McAdams, H. T. September 1985. "Adjusting the Impact Scale in Cross-Impact Analysis: A working Paper Reviewing Impact Matrices," Draft Report to Pacific Northwest Laboratory, Richland, Washington, under Subcontract No. B-M7160$\mathrm{A}-\mathrm{Z}$.

McAdams, H. T. January 1985. "The Lamp-Post Algorithm," Draft Report to Pacific Northwest Laboratory, Richland, Washington, under Subcontract No. B-M7 160-A-Z. 
McLean, Mich. 1976. "Does Cross-Impact Analysis Have a Future?," Futures, pp. 345-349.

Merkhofer, M.W. 1982. "A Process for Technology Assessment Based on Decision Analysis," Technological Forecasting and Social Change, Volume 12, pp. 237-265.

Mitchell, R.B., J. Tydeman, and R. Curnow. 1977. "Scenario Generation: Limitations and Developments in Cross-Impact Analysis, " Futures, pp. 205-211.

Mitroff, Ian I., and Murray Turoff. 1976. "On the Distance Between Cross-Impact Models: A Set of Metric Measures for Cross-Impact Analysis, " Technological Forecasting and Social Change, Volume 8, pp. 275-283.

Mitroff, Ian I., and Murray Turoff. 1973. "Technological Forecasting and Assessment: Science and/or Mythology?," Technological Forecasting and Social Change, volume 5, pp. 113-134.

Nanus, Burt. Futures Research--Stage Three, CFR Information Network, pp. 3-11.

Nehnevajsa, Jiri, and Joshus Menkes. 1981. "Technology Assessment and Risk Anaiysis," Technological Forecasting and Social Change, Volume 19, pp. 245-255.

Preble, Jhon F. 1983. "Public Sector Use of the Delphi Technique," Technological Forecasting Social Change, Volume 23, pp. 75-88.

Price, Brian H. 1983. Implications of Economic Change for the U.S. Geological Survey, Report to U.S. Geological Survey, Contract No. EPA-68-02-3680.

Randall, Robert M. 1984. "Sniping at Strategic Planning," Planning Review, pp. 8-11.

Rao, Dileep R. 1975. A Comparison of Four Techniques of Technological Forecasting: 1. Mathematical Programing, 2. Cross-Impact Analysis, 3. Modified Delphi, 4. Envelope Curve, Thesis submitted to Faculty of Graduate School of the University of Minnesota.

Reilly, George M. 1977. The Use of the Delphi and Cross Impact Matrix Techniques in Educational Policy Planning, Dissertation submitted to Teachers College, Columbia University.

Rescher, Nicholas. 1981. "Methodological Issues in Science and Technology Forecasting: Uses and Limitations in Public Policy Deliberations," Technological Forecasting and Social Change, Volume 20, pp. 101-112.

Rivera, Eduardo, and Ma. Luisa Revilla. 1984. "A Cross-Impact Simulation and Analysis of Events Through Time with a Micro-Computer, "Microprocessing and Microprograming, Volume 13, pp. 189-198. 
Rosentha1, Paul. 1979. Cross-Impact Simulation of an Emerging Industry: A Case Study of Data Processing, Dissertation presented to Faculty of Graduate School of Business Administration, University of Southern California.

Rosenthal, Paul Hervet, 1980. "A Cross-Impact Simulation Forecasting of the Data Processing Industry," National Computer Conference Proceedings, pp. 613-621.

Sahal, Devendra. 1975. "Cross-Impact Analysis and Prediction of Technological Developments: A Case Study of Farm Tractors," IEEE Transactions on Engineering Management, Volume EM-22, No. 2, pp. 76-79.

Sarin, Rakesh K. 1978. "A Sequential Approach to Cross-Impact Analysis," Futures, pp. 53-62.

Schindler, Ralph L. 1979. Development and Evaluation of Cross-Impact Analysis as a Crisis Decision-Aid, Master's Thesis, Naval Postgraduate School.

Shefer, Daniel, and Jacques Stroumsa. 1981. "The Delphi Method: A DecisionMaking Tool for Street-Lighting Planning," Socio-Economic Planning Sciences, Volume 15, No. 5, pp. 263-276.

Stacey, Gary S. 1984. BASICS: Key Global and United States Descriptors, Report to BMI, Battelle's Columbus Division.

Stanford Research Institute. 1974. Cross-Impact Simulation in Water Resource Planning, report prepared for Institute for Water Resources (Army).

Stover, John G., and Theodore J. Gordon. 1978. "Cross-Impact Analysis," in Handbook of Futures Research, Jib Fowles, editor, Greenwood Press, Westport, CT, pp. 301-328.

Stover, John. 1973. "Suggested Improvements to the Delphi-Cross-Impact Technique," Futures, pp. 308-313.

Sullivan, William G. 1978. "A Cross-Impact Analysis of the Solar Space Heating and Cooling Industry," Industrial Management, pp. 17-21.

Swager, William L. 1972. "Strategic Planning I: The Roles of Technological Forecasting," Technological Forecasting and Social Change, Volume 4, pp. 85-99.

Swager, William L. 1972. "Strategic Planning II: Policy Options," Technological Forecasting and Social Change, Volume 4, pp. 151-172.

Swager, William L. 1973. "Strategic Planning III: Objectives and Program Options," Technological Forecasting and Social Change, Volume 4, pp. 283-300.

Sylvan, Donald A., and Stuart J. Thorson. 1980. "Choosing Appropriate Techniques for Socio-Political Forecasting," Policy Sciences, Volume 12, pp. 265-282. 
Technology Futures, Inc. 1982. Technology Forecasting: An Aid to Effective Technology Management.

Turoff, Murray, 1972. "An Alternative Approach to Cross Impact Analysis," Technological forecasting and Social Change, Volume 13, pp. 309-339.

Vertinsky, Patricia A., and William A. Thompson. 1980. "Cross-Impact Computer Simulation of Physical Education Program Priorities: A Systems Perspectives," Research Quarterly for Exercise and Support, Volume 51, No. 2, pp. 389-406.

Vlachos, Evan. "The Use of Scenarios for Social Impact Assessment," pp. 211223.

Watson, Richard H. 1978. "Interpretive Structural Modeling--A Useful Tool for Technology Assessment?," Technological Forecasting and Social Change, Volume 11 , pp. 165-185.

We11, Edward D., and Robert R. Cangemi. 1983. "Linking Long-Range Research to Strategic Planning," Research Management, pp. 32-39.

Weiner, Edith. 1976. "Future Scanning for Trade Groups and Companies, "Harvard Business Review, pp. 14, 174, 176.

Wilson, Ian G. 1978. "Scenarios," in Handbook of Futures Research, Jib Fowles, editor, Greenwood Press, Westport, CT, pp. 225-247.

Wissma, Johan G., and Jan Benes. 1980. "A Cross-Impact Case Study: The Dutch Construction Sector," Futures, pp. 394-404.

Zentner, Rene D. 1975. "Scenarios: A New Tool for Corporate Planners," Chemical and Engineering News, p 22.

Zierden, William E. 1979. "Cross-Impact Matrix and the Futures Wheel: Futures Tools in the $O B$ Class, "Exchange-Organizational Behavior Teaching Journal, No. 4, pp. 40-42. 
APPENDIX B:

DOECIM COMPUTER PRINTOUTS 




Desertptor

1. World Oil Price

2. Economic Growth R

3. Interests Rates

4. Compostion of In

5. T2x \& Invest POIi

6. Product. of NE tac

7. Waste H Recovery

8. Chgs in MEg Tech

9. Cogeneration Tech

10. Indus. Energy Int

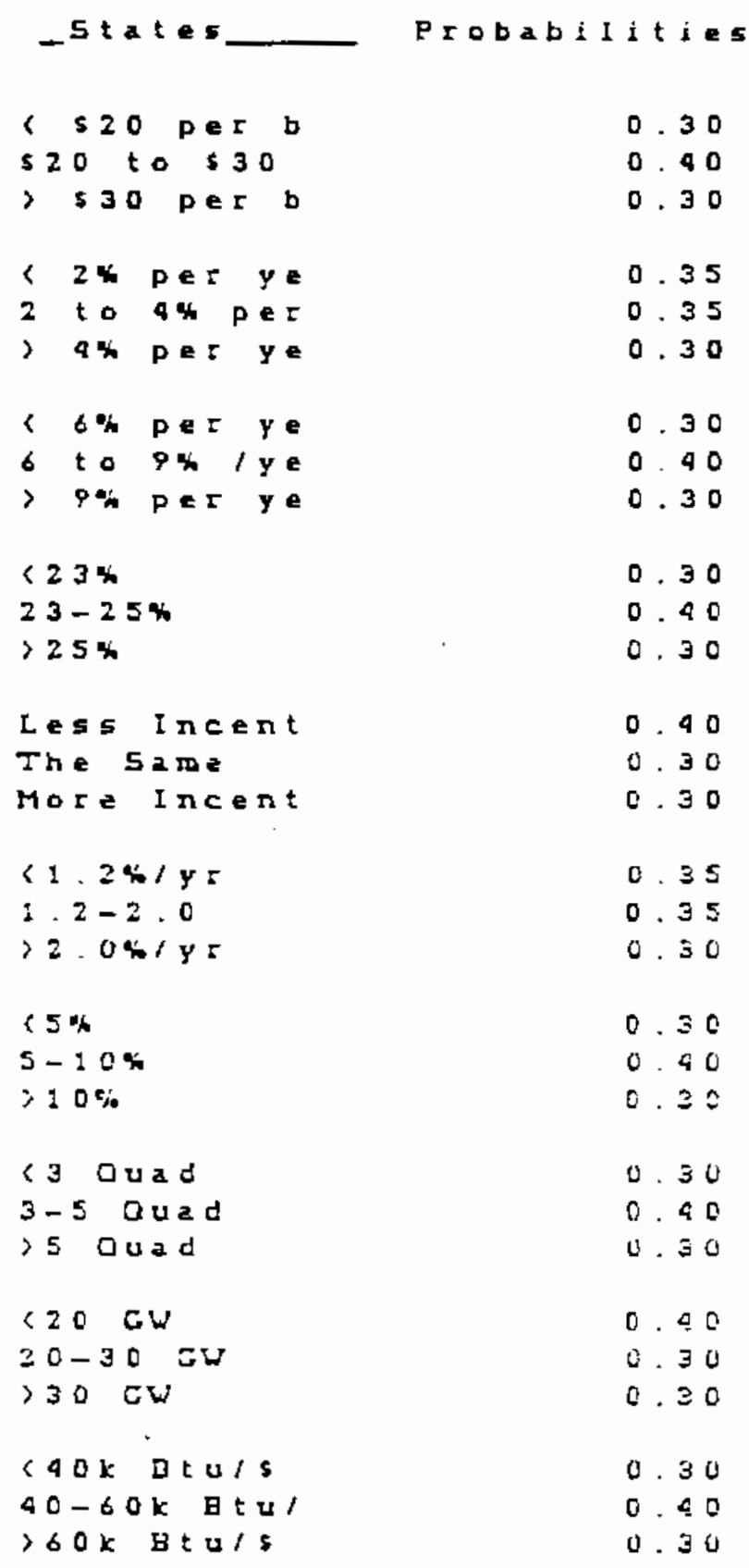




\section{TABLE B.2 Conditional Probability Matrix}

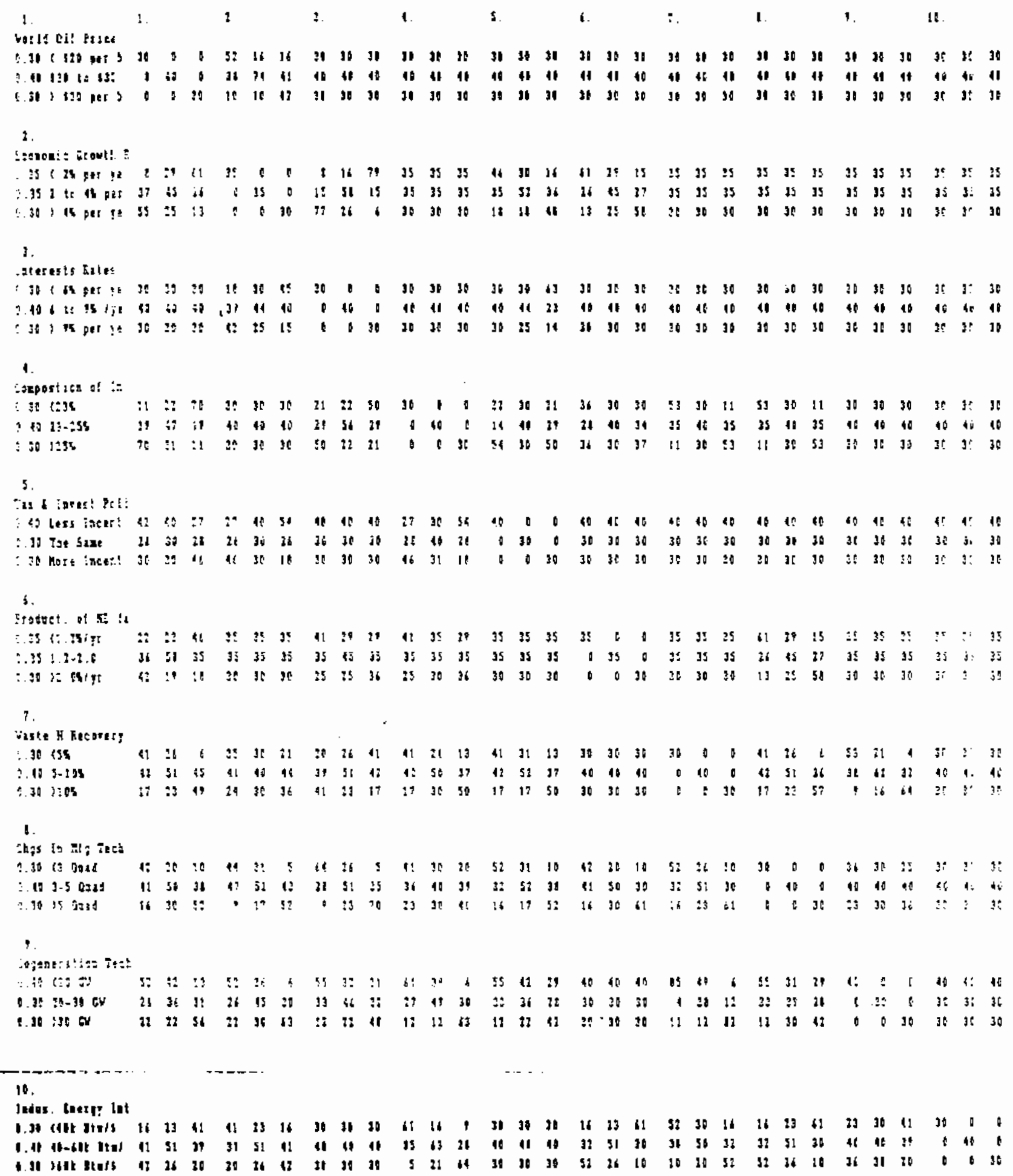

7 .

Viste Hecorer,

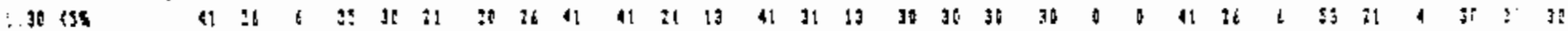

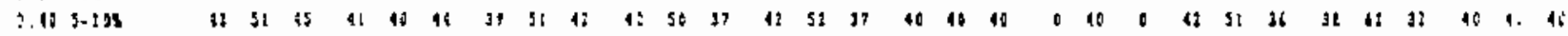



1.

shọs in ath iack

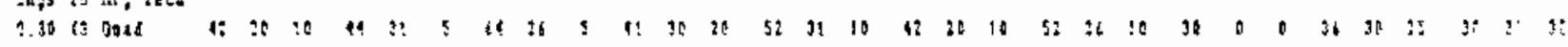

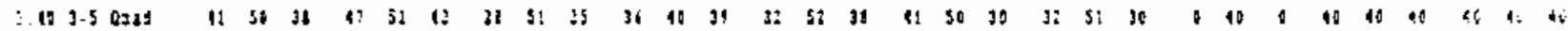

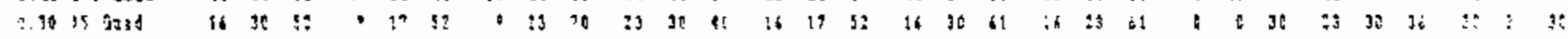

.

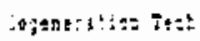

.



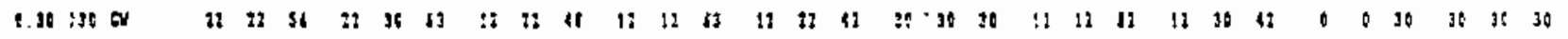

10.

Jedrs. thery: lat

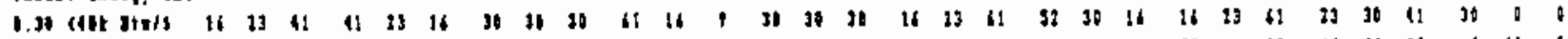

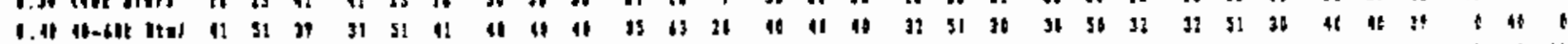

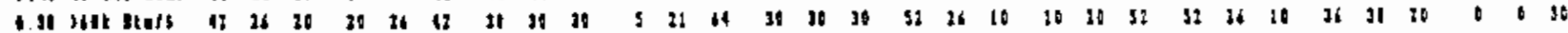


1.

tenagite Growle 1

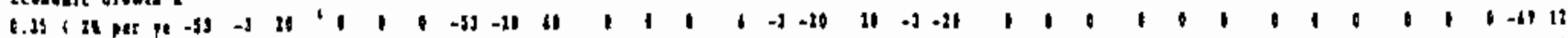

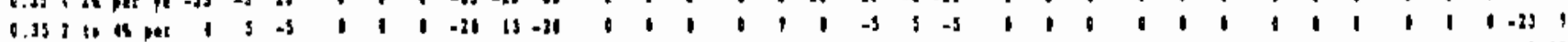

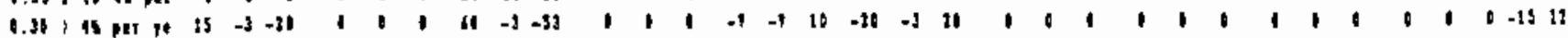

1.

Interests Lates



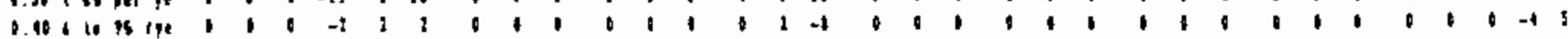

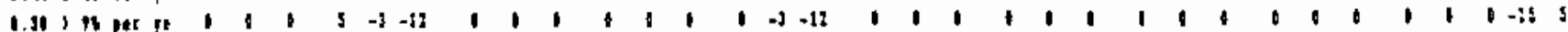

Conpostion of li



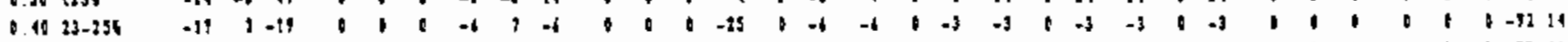

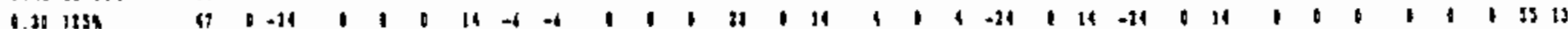

Ta1 : lavest poli

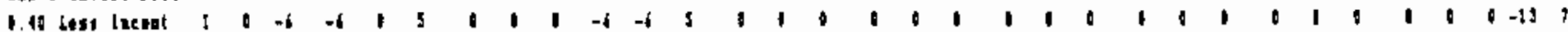



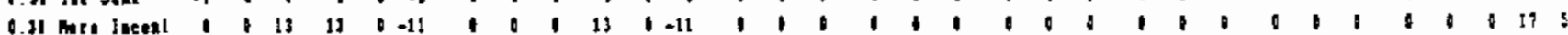

6

Ptedral. al a $\mathrm{d}$

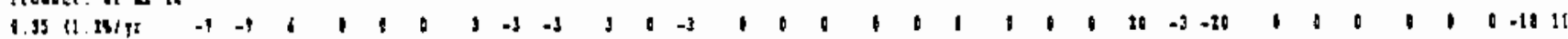

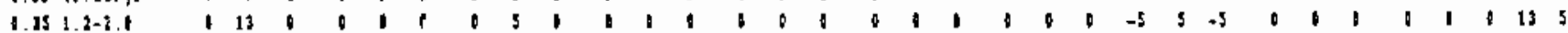

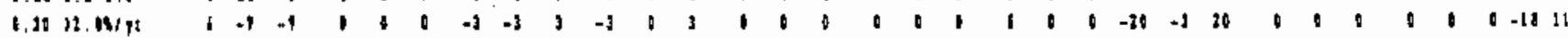

,

biste E lecourt

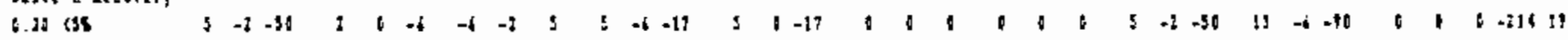

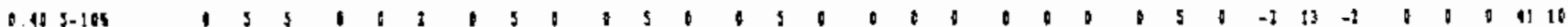

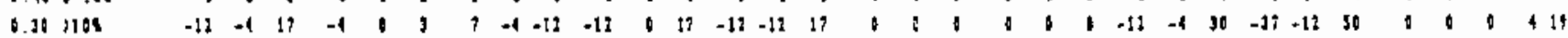

4.

Cleges lo Mitg ieck

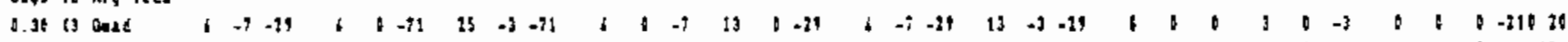

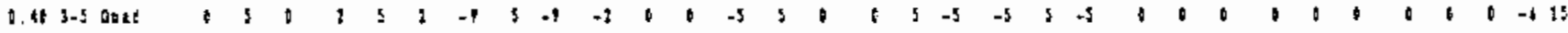

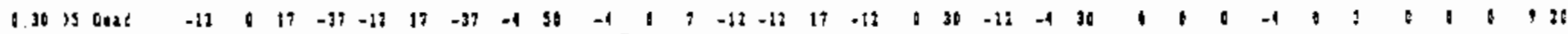

1.

Cogesecetion Teeb

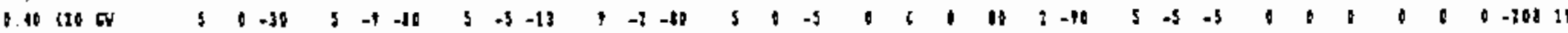

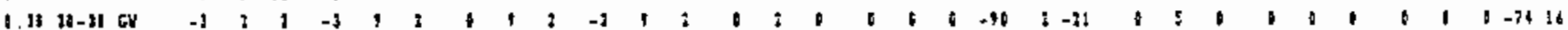

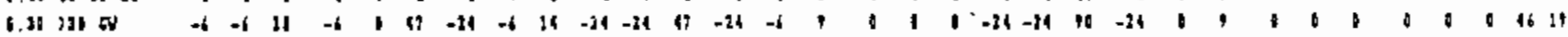

It.

Ines. Laergr tat

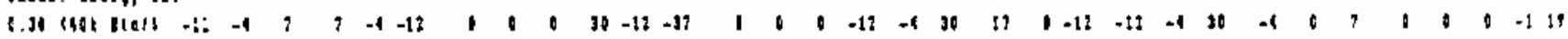

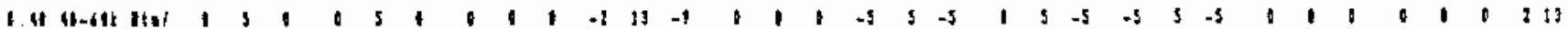

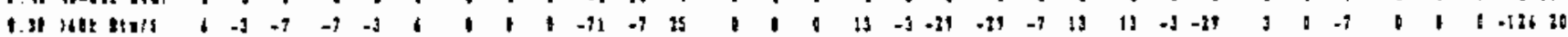

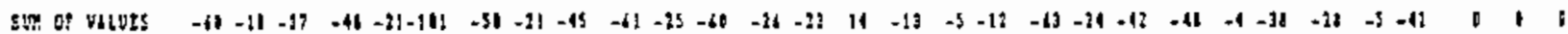

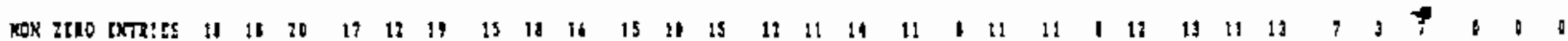


IABLE B.4 Analysis of Driver and Driven Descriptors

Indostrial Situation Mod. 14-rariables 1/23/16

AHCTIS Of DRIVER GESCRIPTORS



AMLTSIS OF DRIYEN DESCRIPTOHS

Driven Desctiptors

Arerage of 5late lepats

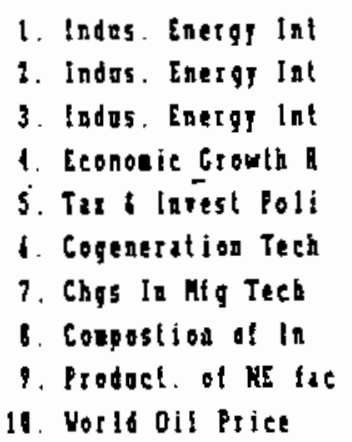

14

18

11

.16

16

If

11

1

s

5 
IABLE B.5 Base-Case Simulation

Indonlitel slindlen ked. Henelibles

Irim



\begin{tabular}{|c|c|c|c|c|}
\hline Jaln Robablits & 1.1111 & 1.1011 & I IHI & 1.1114 \\
\hline nledate Habbill1, & I.ns & 1.111 & 1.101 & f.1111 \\
\hline Kurlens Relsbllll, & tht & 1. & 1.13 & I. III \\
\hline Stendice oreletles & 1111 & 1.111 & 1.1111 & 1111 \\
\hline stredurdiced Hobblally & 1.1114 & I IHII & 1111 & 0.1131 \\
\hline
\end{tabular}

III 1, 111 111 10 134

11011 p.

I 1. " .".

11,1119

110111

inss

comestlen it it

111

Lril incent

Leil Inent

1.2.1.

rodati. il ne be

Viste n necouts

EhP II RI, Tet

copeneililen trek

Indos. Ineen lit
1.1-1.1

III

1.501 .1

III 6

11-41! 11 .
III

11001

III EN

11. 1110101
12110131

1 1. 14 111

110112

win

lest Ineest

$|1| 1 \mid$

111

1.5010

in ov

(a) It)
11018

614 ine

1138

tols 1xent

11. M11

nin

is 0011

III eV

11-111 110

\section{1. 131}

$1018 \mathrm{per}$

(1) II

mix

tiss Inseet

1.2.2.

11"

150.11

II) EV

III Itat

$\begin{array}{ll}1.111 & 1.111 \\ 1.1111 & 1.111 \\ 1.111 & 1.111 \\ 1.113 & 1.111 \\ 1.111 & 1.111\end{array}$



IIt 1. III

1111811

1 $1.121 \mathrm{~s}$

113

lens leetul

II Nip

ith

11001

III $\mathrm{cy}$

1411 11011

\section{(11)}

(4) 10

11. 13 118

ins

lits tacen

11. suit

(s)

(1) 0.11

111 ev

He Itoll
I III

(1) ".. "

(1)

IIs

test Inesel

(I MIt"

s-1ts

19 $0+1$

11- 11 CV

(II) $\mathrm{nell}$

1.111
1.114
1.011
1.111
1.011

I.I11

1. olit

1111

1.111

1.11ts

tit pet

( 11 11 14

1. 12 tpe

uss

lin lacent

a tur

111

110011

III ev

111 IIII 
TABLE B.6 Base-Case Slinulation with Lower Threshold

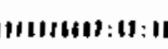

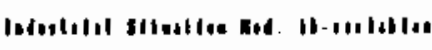

14. i1

ImII

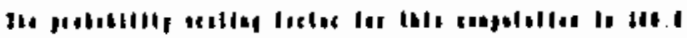

\begin{tabular}{|c|c|c|c|c|c|c|c|c|c|c|}
\hline folat latiblllts & I. M11 & 1:H11 & 1.dus & D. 11 & .114 & 1.1611 & 1.1141 & 6.1116 & (1)t & l 111 \\
\hline  & 1.111 & 1111 & I.III & 1.111 & 1.111 & c.lons & $1 \mathrm{Mas}$ & 1111 & 1111 & 1 แH \\
\hline Muleun Hetillill, & C.MIH & 1 נו & $1 \mathrm{MH}$ & - ItII & 1.311 & I. mit & I. HII & 1.2111 & 1.1131 & $1 \mathrm{MHI}$ \\
\hline "1+1,1 bulalls, & (.111 & 1.1111 & 1.111 & 1 111 & 1 III & 1.111 & 1116 & $1 m$ & I Ist & $1 \mathrm{HI}$ \\
\hline 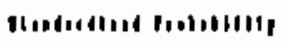 & 1. III & 1.1111 & Im & 1.1111 & 1111 & . 11019 & 1.c1sts & 1.uns & 1.1111 & 1111 \\
\hline Villd oll liles & $111+10$ & 1111,131 & $11 ! 1,11$ & 111 (1) 111 & 111111 & 111,11 & 1111 & 136111 & I 111010 & ( ItI pert \\
\hline Atruele bionle I & 11015 & 11018 & $11,18 \mathrm{nt}$ & 1121214 & 11.411 & $11,11,10$ & 11014 & 10 pecte & 1914 & 118,14 \\
\hline 101110110 l11.1 & 61.11112 & 11110 & יו/ 1. & 11.8110 & $110 \mathrm{nt}$ & $11+1114$ & 161,110 & 148011 & 161110 & 11011 \\
\hline senentiloe of is & ms: & 1118. & Iass & ms & H1 & $m x$ & 13s & 11-135 & nss & 3138 \\
\hline ba l lanst Pall & late lacest & loll loent & but thetel & Lact Iecanl & lat lecedt & lont Inteel & las Inetel & Mert betiet & los lecel & Las lacent \\
\hline Motret. of at be & 1.1 .1$. & 1.1 .11 & $1.1-11$ & $11.16 / 1$ & 1.1 .1 .1 & II. & $\| M_{n}$ & 11.111 & $\|m\|$ & " wו" \\
\hline ville | Nenters & 116 & 1111 & 113 & 314 & mas & was & ist & 118 & $11 \mathbf{k}$ & ins \\
\hline an, he nt, bact & $1-10.14$ & 11 a., & 1.100 .1 & Is a.1 & 13801 & 21 & 11 de., & 11001 & 11 And & 11001 \\
\hline Cobrecelllon Tert & III $x$ & ) & III cy & $111 \mathrm{EV}$ & III & $216 \mathrm{ct}$ & III cV & II cy & M co & III 6 \\
\hline laves. Forref dat & 11. tI 11.1 & (1.41 It) & आII & (1). 11 H H. & tII & III II, & 141111011 & (111 J1a) & (16) 11.14 & M1114 \\
\hline
\end{tabular}


APPENDIX C - SAMPLE DESCRIPTOR ESSAYS 


\section{INTEREST RATES}

\subsection{DESCRIPTION}

The interest rate is the price associated with borrowing money; for this reason, it is often called the time value of money. There coexist many different rates of interest, depending on the length of borrowing, the institution involved, and the risk associated with the borrower. Generally interest rates are higher the longer the borrowing period and the riskier the loan. Over long periods of time, one observes that these rates move together, so if short rates for secure loans increase, so too, generally, do longer rates for the same risk class of loans. Because of this coincident movement, a single rate of interest can represent all rates over a fairly long period of time. For this exercise, an appropriate rate is the prime rate -- an often quoted rate that represents "the interest rate banks charge their most creditworthy business custormers for short-term loans. It is the base rate used to scale upward the rates charged on most loans to other business customers." (SCB, 7/85)

\subsection{RATIONALE}

Interest rates are important factors in determining the environment for energy use efficiency and consumption in the residental sector both directly and indirectly. Interest rates are directly important because they influence the availability of financing for new home purchases, appliance purchases and residential building retrofits and because of the costs associated with lost opportunities can influence both attitudes toward energy conservation and the availability of conservation programs. They are indirectly important through their influence on both energy and non-energy prices and personal income. Because these causal interactions are so vital to this study, it is worth elaborating on how the interest rate will effect energy efficiency and consumption in somewhat more detail.

The indirect effects on energy efficiency and consumption in the residential sector arise from the role of interest rates in general economic policy. Elementary textbook examples suggest that monetary authorities will intervene in financial markets to maintain interest rates or the money supply

$$
\text { C.1 }
$$


within a targeted range. These targets will be determined by the appropriate monetray policy for existing economic conditions -- during periods of rising prices these targets will be restrictive to stifle inflation; during periods of low economic activity, the targets will be expansionary to promote growth. High interest rates, then, generally indicate a tightening of credit, lower rates a loosening of credit. If the monetary authorities are successful in "leaning against the wind," it is likely that high interest rates would be associated with high rates of inflation, while lower rates would be associated with periods of relative price stability. Abstracting from price changes, more rapid rates of growth in the economy would be associated with lower interest rates, while slower rates of economic growth would be associated with higher interest rates. (a) But textbook conditions rarely exist.

During recessions -- real economic decline -- one would expect the monetary authorities to ease credit conditions, the tightness of which might have been a partial cause of the decline. If so, one could select a time when growth rates were high and interest rates were rising or vice-versa. Alternatively, during periods of "stagflation" (stagnent growth and inflation), the monetary authorities would be caught on the horns of a dilemma: slow growth suggests easing credit conditions while inflation suggests tightening credit. So in mapping out the linkages, one must clearly differentiate between causal effect and coincident events. If monetary authorities respond to indications of adverse economic events, which is likeiy, interest rates will go up during periods of inflation and down during periods of low or negative economic growth. But what do the monetary authorities do when, as recently, the economy experiences both high inflation and low economic growth? Clearly the monetary authorities must choose. How they have reconciled these inconsistent objective is an empirical matter; the results of these actions will be discussed in the next section.

The direct effects of interest rates on energy efficiency and use is less ambiguous. As an indicator of the cost of borrowing, interest rates will influence the costs of purchases of home appliances, the costs of retrofitting of residential buildings to make them more energy efficient, and

(a) See Rasche for alternative theories of interest rates. 
the purchases of new homes. The rate of additions to housing stocks and the penetration of newer (and therefore more efficient) appliances both will clearly increase the efficiency of energy use in the residential sector. Any additions to either housing or appliance stocks will increase energy use; retrofits to existing stock or replacement of older stocks will decrease energy use. The cost of borrowing will also be a major factor in the decision to winterize existing homes since the costs of borrowing will determine the payback period for the retrofit.

\subsection{HISTORICAL TRENDS}

The prime rate over the period 1950 to 1984 is plotted as the solid line in Figure 1. Over the 35 years covered in the graph what stands out most dramatically is the secular increase in the prime rate -- averaging about three percent after the Treasury Accord of 1952, with gradual rises through the mid-1960's, then increasing sharply to average about 13 percent during the early 1980 's. One would have to go back before 1929 to see average interest rates that exceeded the prime rate in 1965. But relying on the trend over the past 35 years as a basis for projecting trends in interest rates into the future would be a mistake. A comparison of movements in the rate of inflation (plotted in Figure 1 with short dashes) and the prime rate since the Treasury Accord indicates that both of these variables move in much the same manner, with a historic differential of about 2-3 percent. This differential is a close approximation to a "real rate of interest" -- the value of money adjusted for the losses that results from inflation.

This measure of the real rate of interest is only approximate because decisions are based on anticipated rates of inflation that can be foreseen only vaguely. Nonetheless, any trend in interest rates must take into account the likelihood that real rates of interest will reflect a more normal historic relationship between the prime rate and the rate of inflation. It is only during periods of sharp changes in the rate of inflation or economic recessing that these historic relationships are badly disturbed. 




\subsection{CURRENT STATUS}

Since October, 1979, the Federal Reserve System has pursued a generally restrictive monetary policy using two different stabilization procedures. The first, from 1979 till the end of 1982, focused on the money supply as the main intermediate target. As a result of this policy, interest rates bore the principal burden of adjustment to financial disequilibrium (Tobin). Over the period when the money supply served as the primary target, interest rates were both higher and more volatile than in any recent period of history. Since 1982, the Federal Reserve has used interest rates as the main intermediate target, with the money supply serving as a secondary target. The consequence of this change has been a reduction in the variation of interest rates with 
somewhat more volatility in the money supply and less day-to-day variation in interest rates. This reduction in interest rate variation has had the effect of lowering interest rates through the reduction in uncertainty about future interest rates.

This shift in Federal Reserve procedure, and a consistently restrictive monetary policy has combined with a series of recessions to lower both interest rates and the rate of inflation between 1980 and 1983. From a high of nearly 19 percent in 1980, the prime rate has fallen to a current level of slightly about 10 percent. The rate of inflation has also declined substantially from a high of over 13 percent in 1980 to 3.2 percent in 1983, moving back up to 4.3 percent in 1984 . The weakness in the economic recovery that has become evident in early 1985 suggests that a resurgence of inflation to rates higher than 5 or 6 percent is unlikely any time soon.

With lower inflation rates that persist for some time, financial institutions and borrowers will lower their expectations about future rates of inflation; lower expectations, in turn, will lead to a return to a more historic differential between inflation and interest rates. The current differential remains much higher than historically has been common. Since 1981, the differential has averaged above 7 percent, but recently that differential has begun to narrow. With the perception of a continuing restrictive monetary policy, a course of action about which the Federal Reserve has been convincing, and no major external price shock such as the oil price shock of the early 1970 's, it is likely that inflation will continue at reasonably low levels and that interest rates will gradually move back into historical relationship with inflation.

\subsection{FUTURE PROSPECTS}

If the rate of inflation returns to the more modest rates of the late 1960 's, which ranged from 2 to 6 percent, we could expect the prime rate to remain below double-digit rates. But if inflation persists at levels similar to the rates that have prevailed since the first OPEC price shock of 1973-74 (ranging from 6 to 13 percent), the prime rate would more likely stay within a range from 9 to 16 percent. The major area of uncertainty is how quickly 
the historical differentials between interest rates and inflation will return.

Figure 1 also plots forecasts of inflation and the prime interest rate for the period 1985-1990, based on the forecasts of Data Resources, Inc. (DRI). The DRI forecasts through 1995 predict inflation rates that climb annually to 6.5 percent in 1995, with a declining prime rate that reaches a low slightly above 9 percent in 1995. With a change in monetary policy back to interest rate targets and a sustained lower rate of inflation, our forecasts would have this historic differential achieved much sooner than the DRI forecast suggests. Accordingly, the descriptor states and a priori probabilities associated with then are as follows.

$\begin{array}{lc}\text { Descriptor States } & \text { A Priori Probability } \\ \text { Above } 9 \text { percent } & .35 \\ \text { From } 6 \text { to } 9 \text { percent } & .55 \\ \text { Below } 6 \text { percent } & .10\end{array}$

The probabilities associated with these descriptor states are contingent on the forecasts for the rate of inflation and assume a return to historic differentials between these two variables well before the 1995 period. At the same time, recent events have aptly demonstrated that this differential may deviate within wide limits, as may the forecasts (Bernstein and Silbert).

\subsection{REFERENCES}

P. L. Bernstein and T. H. Silbert, "Are Economic Forecasts Worth Listening To?," Harvard Business Review, September/October, 1984.

Economic Report of the President, 1985. U. S. Government Printing Office, Washington, D. C.

Robert H. Rasche, "Views on Deficits and Interest Rates," FRBSF Weekly Letter, Federal Reserve Bank of San Francisco, April 19, 1985.

Survey of Current Business, "The Prime Rate," U. S. Department of Commerce, USGPO, Washington, D. C., July, 1984, p. S-36.

James Tobin, "Monetarism: An Ebbing Tide?" The Economist, April 27, 1985, pp. 23-25. 


\section{COMPOSITION OF INDUSTRY}

\subsection{DESCRIPTOR}

There are several aspects about composition that are important in determining the environment for energy use and efficiency in the industrial sector. One is the contribution to domestic output by the industrial sector; another is the fraction that energy intensive or energy consumptive industries contribute to industrial output. For this study attention will focus on the latter question. A measurement of the fraction of the industrial sector that is produced by the most energy intensive and energy consumptive industries will be used. This measurement is operationalized by dividing total industrial sector GNP--from agriculture, mining, construction and manufacturing--into GNP originating in food processing; pulp and paper; petroleum refining; chemicals; stone, clay and glass; and primary metals. These six manufacturing industries account for about 60 percent (63 percent in 1977) of total manufacturing energy consumption and are the most intensive users of energy in the industrial sector.

\subsection{RATIONALE}

The composition of the industrial sector is an important factor in determining energy use efficiency and consumption, for a number of reasons. One obvious reason is that as the share of energy consumptive industries is altered, the share of energy consumed will change para pasu. Such a change can be the consequence of a number of different effects. Energy consumptive industries' share of industrial output may decline (increase) as consumers purchase less (more) of goods that contain products produced by these industries or as we import more of these goods. Alternatively, other industries may purchase less (more) of energy consumptive industries' output as intermediate materials, thus reducing (increasing) the fraction of output produced by the energy consumptive sector of industry.

A second reason that the industrial composition is important is because the more energy intensive industries provide the best opportunities for economizing on energy use. Economic theory argues that the responsiveness of a 
business to changes in, for example, the price of energy, will be the more dramatic, the larger fraction energy is of the total cost of the product that business produces. Thus the response of industry to changing costs of energy will be greater, the more energy used and the more energy intensive that industry is.

A final reason that industrial composition is important is because it is so closely linked with a number of other factors that effect the environment for energy use intensity and consumption in the industrial sector. International trade has dramatically altered the way that the iron and steel industry is used in this country and the iron and steel industry is a major consumer of energy. If energy prices increase, and these price increase are passed along to final consumers, as they must ultimately be, products that use much energy will experience higher price increases and thus there will be more incentive to substitute for these goods. Energy technology will also be influenced as the composition of industry changes since it is within the more energy intensive and energy consumptive industries that there exists the most incentive for the adoption of conservation technologies. And indirectly there are linkages to the productivity of non-energy factors of production and to cogeneration. A final, and very direct relationship exists between the composition of the industrial sector and this sector's energy use intensity, since the sector energy use intensity will vary directly as the fraction of high energy intensive industries to the total industrial sector varies.

\subsection{HISTORICAL TRENDS}

Figure C.2 plots two ratios: the historical ratio of energy intensive and energy consumptive industries to total industrial sector output, as measured by this sector's contribution to GNP (which will be called the composition index) and the proportion that manufacturing is of total industrial output.

It is clear from Figure C.2 that manufacturing has been an increasing percentage of the industrial sector since the late 1950's. Manufacturing has increased from about 65 percent of the industrial sector in 1950 to over 75 percent currently. This has happened as growth in agriculture, mining and construction has not kept pace with the growth of manufacturing. Despite 


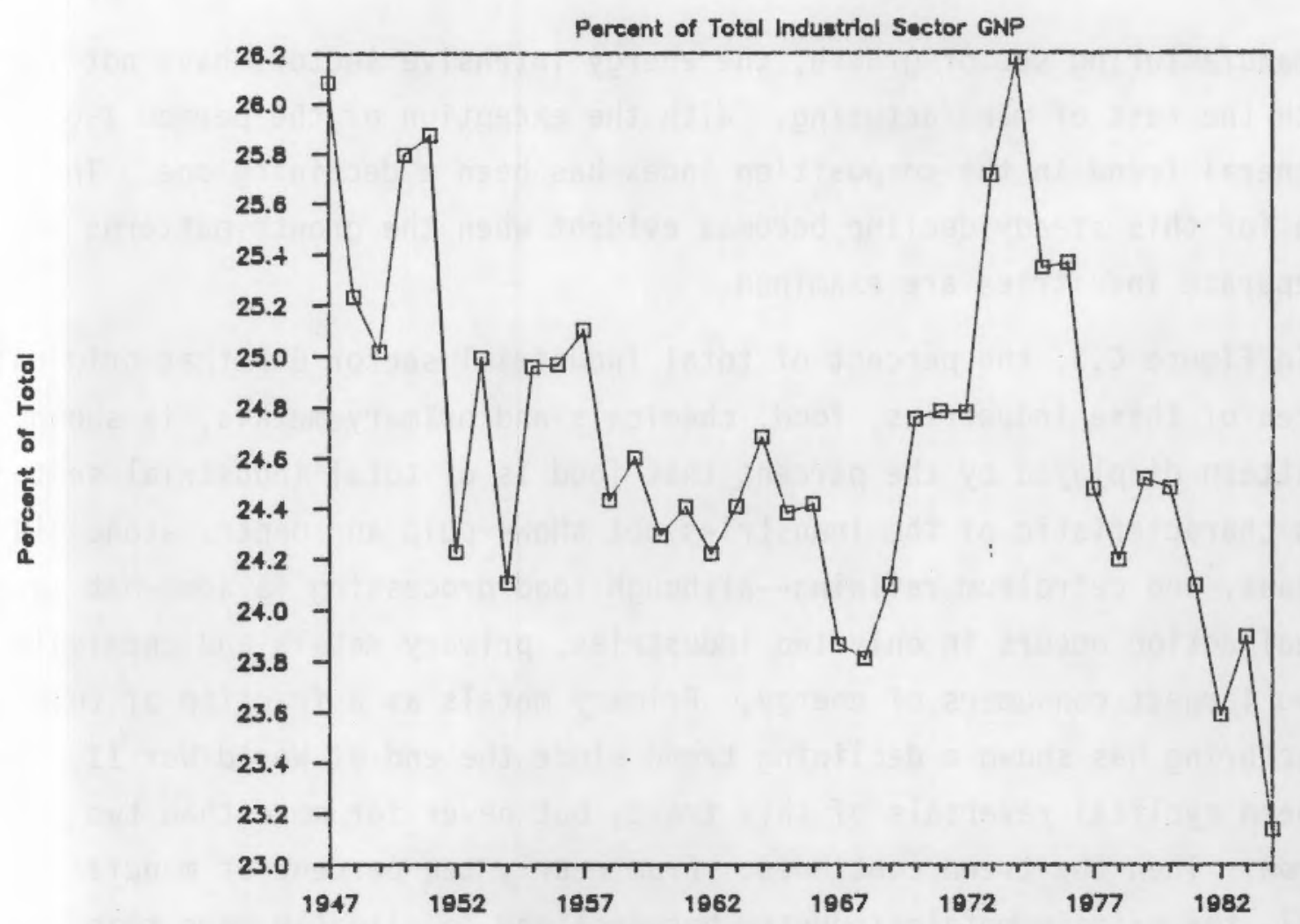

FIGURE C.2 Panel A: Ratio of Energy Intensive Industries to Sector GNP

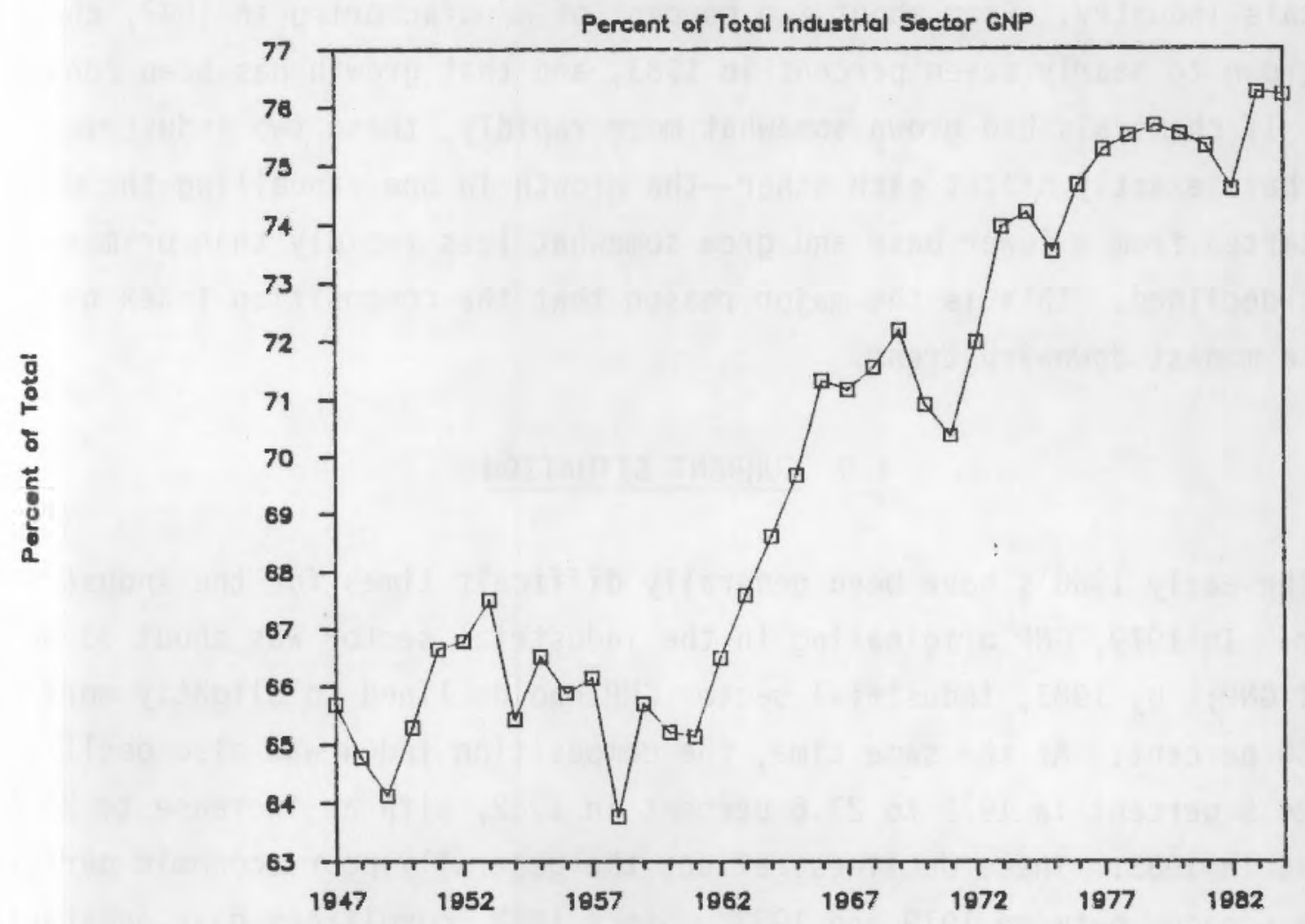

FIGURE C.2 Panel B: Ratio of Manufacturing to Sector GNP C.9 
this manufacturing sector growth, the energy intensive sectors have not kept up with the rest of manufacturing. With the exception of the period 1968-1974, the general trend in the composition index has been a declining one. The reason for this steady decline becomes evident when the growth patterns of the separate industries are examined.

In Figure C.3, the percent of total industrial sector GNP that originates in three of these industries, food, chemicals and primary metals, is shown. The pattern displayed by the percent that food is of total industrial sector GNP is characteristic of the industries not show--pulp and paper, stone clay and glass, and petroleum refining--although food processing is somewhat larger. The real action occurs in only two industries, primary metals and chemicals, the two largest consumers of energy. Primary metals as a fraction of total manufacturing has shown a declining trend since the end of World War II. There have been cyclical reversals of this trend, but never for more than two years in a row. Then the trend continues. From nearly ten percent of manufacturing in 1947, the primary metals industry has declined to slightly more than three percent in 1983. Somewhat offsetting this decline has been the growth of the chemicals industry. From about two percent of manufacturing in 1947, chemicals have grown to nearly seven percent in 1983, and that growth has been consistent. If chemicals had grown somewhat more rapidly, these two industries would have exactly offset each other--the growth in one cancelling the other. But started from a lower base and grew somewhat less rapidly than primary metals declined. This is the major reason that the composition index has shown a modest downward trend.

\subsection{CURRENT SITUATION}

The early 1980's have been generally difficult times for the industrial sector. In 1979, GNP originating in the industrial sector was about 33 percent of all GNP; by 1983, industrial sector GNP had declined to slightly more than 30 percent. At the same time, the composition index was also declining from 24.5 percent in 1979 to 23.6 percent in 1982, with an increase to 23.9 percent in 1983. These declines reflect the generally poor economic performance of the economy between 1979 and 1982. Since 1982, conditions have substantially 




FIGURE C.3 Ratio of Selected Industries to Sector GNP

improved. The energy intensive industries have all experienced a resurgence of output and the economy has recovered. This is especially evident in the growth of manufacturing as a fraction of total industrial GNP in 1983. Will this improvement continue, and will the energy intensive industries retain their relative position in the industrial sector, or will they continue their historic decline?

\subsection{FUTURE PROSPECTS}

of the two industries that have shown substantial movement relative to the industrial sector total, chemicals and primary metals, it seems unlikely that both these trends will continue. Primary metals have declined from nearly 10 percent of total industrial sector GNP to slightly more than three percent. This decline will most certainly slow, and may even end. Even if many integrated iron and steel plants ceased to operate domestically, mini-mills, with their cost advantage, will continue to supply up to about half the current market. This suggests that although steel may continue to decline, the rate at which it declines will be reduced. And what holds for steel will likely hold for the other primary metals. On the other hand, the prospect for con- 
tinued growth in chemicals is favorable. The major change in the chemical industry recently has been the shift from the production of bulk chemicals to the production of speciality, high valued chemicals. These high valued chemicals are typically produced close to their markets to reduce shipping costs, so growth in this segment of the chemical industry shows up as generating more GNP, thus increasing its share in industrial sector GNP. A moderation in the reduction of primary metal growth and a continued growth in chemicals suggests the following a priori probabilities for the growth in the composition of the industrial sector.

$\begin{array}{ll}\text { Descriptor States } & \text { A Priori Probab } \\ \text { Composition Index Trend } & \\ \text { Declines to below } 22 \text { percent } & 0.15 \\ \text { Remains in the range } 23-25 \% & 0.70 \\ \text { Increases above } 25 \text { percent } & 0.15\end{array}$

\subsection{REFERENCES}

U. S. Department of Commerce, Bureau of Economic Analysis. 1984. "Revised Estimates of the National Income and Product Accounts, " Survey of Current Business. 64 (7), pp. 20-100. (Earlier July issues provided data prior to 1980.)

U. S. Department of Commerce, International Trade Administration. 1985. U. S. Industrial Outlook. Chapters on Primary Metals and Chemicals (11-17, $1 \overline{9}$ and 20). 
APPENDIX D:

THE LAMP POST ALGORITHM 


\section{THE LAMP POST ALGORITHM}

There is the story of the drunk searching frantically under a street light for his car keys. It was not because that was where he lost them but because the light was better there.

There is a lesson for cross-impact analysis here. If we want to locate those joint events having the highest probabilities of occurrence, perhaps we should look for them where they are most likely to be found -- that is, among the high-valued priori and conditional probabilities.

It is straightforward and relatively easy, albeit time consuming, to search every "path" through the probability matrix governing a cross-impact exercise. Each path consists of a sequence of states, one chosen from each variable, and the joint-event probability is computed as a product of appropriate a priori and conditional probabilities.

These probabilities are selected so that they form a linked chain of states. For example, if we initialize on state $A$, then the probability of the joint even $(A, B, C, D)$ can be computed as

$$
\operatorname{Pr}(A, B, C, D)=\operatorname{Pr}(A / A) * \operatorname{Pr}(B / A) * \operatorname{Pr}(C / B) * \operatorname{Pr}(D / C)
$$

The notation $\operatorname{Pr}(\mathrm{A} / \mathrm{A})$ simply denotes the a priori probability of occurrence for state $A$, but in what follows it will be convenient to treat a priori probabilities as conditionals--i.e., as "self conditionals. In other words, at each stage of the probability multiplication, the incoming state must be conditioned on the state just admitted to the calculation at the previous stage. We refer to this sequence of calculations as "chaining" probabilities.

Each branch of a search tree is known to exhibit the chaining or linkage property, because that is how the branch is constructed, but no attention is given to whether the probabilities encountered along the way are high or low. A complete search of the tree requires that all branches be exhausted. However, if several of the nodes in a branch exhibit very low probabilities, there would seem to be little point in following that particular path, even though "the light is good."

The Lamp Post algorithm changes all that. Instead of searching all paths known to be linked, we restrict attention to a subset of high-valued a priori

\section{1}


and conditional probabilities and ask whether these probabilities can be linked into one or more paths.

Computers can do that sort of thing. In the following paragraphs we shown how the Lamp Post algorithm works. The first section treats a global environment, the second section a hierarchical environment. The final section discusses briefly the implementation of the Lamp Post algorithm in DOECIM.

\section{D.1 THE GLOBAL ENVIRONMENT}

For a given cross-impact exercise, the problem is completely defined by a square matrix of a priori (self conditioned) and conditional probabilities. The size of the matrix is $\mathrm{N} \times \mathrm{N}$, where $\mathrm{N}$ is the total number of states. In the example problem we use to illustrate the algorithm, the matrix is $9 \times 9$ [three variables, each with three states (see Table D.1)]. In a realistic problem environment, there might be up to 50 or more states, and the number of cells in the matrix could run into the thousands. And, of course, the astronomical number of possible search paths in such an environment has been noted in Section 7.0 .

\section{D.1.1 The Principle of Thresholding}

The key element of the Lamp Post algorithm is thresholding. It is the mechanism by which a probability matrix, such as the one of Table 0.1 is "thinned out" by removing all those a priori and conditional probabilities below a specified threshold level. The resulting matrix can be made as "sparse" as desired in the interest of circumventing needless and unrewarding search.

The thresholding principle can be illustrated graphically with the aid of Figure D.1, a "three-dimensional" perspective plot of the matrix of Table D.1. The rows and columns of the matrix define the base or "zero-level" plane, and the heights of the bars represent he corresponding a priori and conditional probabilities. Since probabilities are by definition non-negative, Figure D.1 can be thought of as representing Table D.1 "thresholded" at zero.

Now consider raising the threshold to 25 . Here probabilities are shown only if they equal or exceed 0.25 . In figure D.1, all the bars in column D1 and Row D9 that are shaded would now disappear, thus there would only be five bars above the threshold in column D1 (rows D1, D4, D5, D7 and D8), and only 


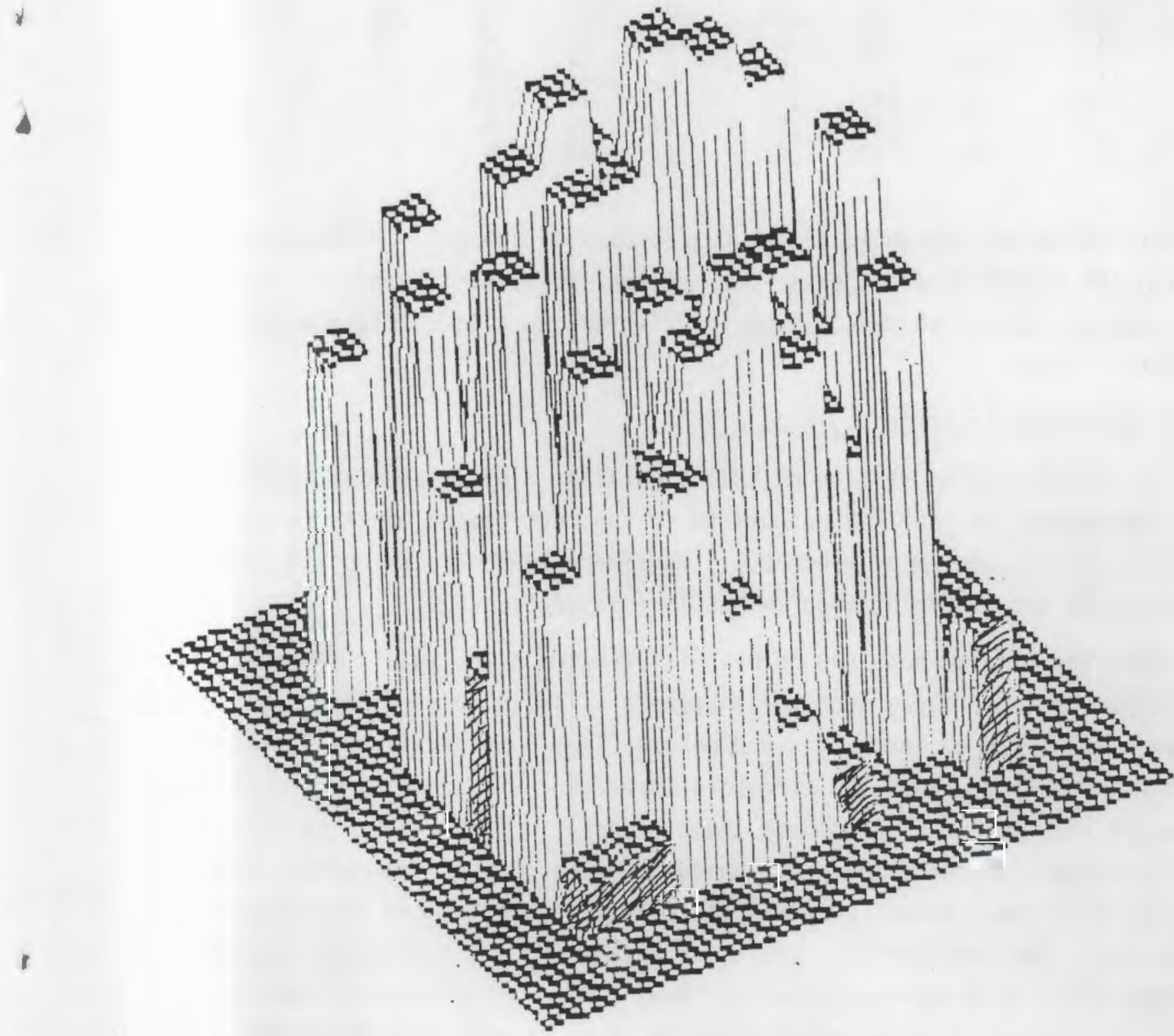

FIGURE D.1 Probability Matrix at Threshold of Zero 
TABLE D.1 Example Conditional Probability Matrix

States

\begin{tabular}{llllllllll} 
States & D1 & D2 & D3 & D4 & D5 & D6 & D7 & D8 & D9 \\
\cline { 1 - 5 } D1 & .35 & 0 & 0 & .22 & .30 & .47 & .09 & .38 & .46 \\
D2 & 0 & .50 & 0 & .51 & .57 & .46 & .59 & .56 & .51 \\
D3 & 0 & 0 & .15 & .27 & .13 & .07 & .32 & .06 & .03 \\
D4 & .50 & .29 & .08 & .20 & 0 & 0 & .10 & .40 & .28 \\
D5 & .33 & .53 & .30 & 0 & .45 & 0 & .42 & .35 & .54 \\
D6 & .17 & .18 & .63 & 0 & 0 & .35 & .48 & .25 & .18 \\
D7 & .62 & .41 & .18 & .22 & .30 & .47 & .35 & 0 & 0 \\
D8 & .33 & .53 & .40 & .51 & .57 & .46 & 0 & .50 & 0 \\
D9 & .05 & .06 & .42 & .27 & .13 & .07 & 0 & 0 & .15
\end{tabular}

two bars above the threshold in row D9 (columns D3 and D4). Progressively raising the threshold would cause more of these bars to disappear. If raised high enough, say 55, there would be insufficient bars to complete a path through the three slates.

\section{D.1.2 Lamp Post in Action -- Globally}

To illustrate the working of this algorithm, a basic problem is used that implements the LAMP POST algorithm in the environment of the threevariable sample problem of Table D.1. Considerable modification the program was required for implementation in DOECIN (see section D.3).

What the program does can be best illustrated by example. Table D.2 is the output of the program when the threshold is set at 0.45 . First the program examines all cells of the matrix and deletes from consideration all probabilities which fail to reach the threshold specified. The remaining probabilities represent the "Number of Candidate Items," shown in Table 0.2 to be 22 in this instance. In the global environment, however, we are concerned only with the self-conditioned (initial) states which survive, and the algorithm finds them. The computer thus starts with each one and follows all possible linkages until it either encounters a "dead end" or completes the decision branch all the way to a completed scenario (i.e., states from three descriptors are included).

In Table D.2, only four paths were capable of being completed. When sorted according to probability magnitude, these four probabilities are seen to lie between 0.136 and 0.151 (note that the minimum which could have emerged 
is $\left.0.45^{3}=0.091125\right)$. Note that all the paths specify a single scenario $=$ $\mathrm{D} 2: 05: \mathrm{D} 8$.

Suppose that the number of candidate items had been considered excessive. The problem can be further "cut down to size" by raising the threshold. In Table D. 3 the threshold is set at 0.5 Now there are only 15 candidate items and only two paths survive. Note that the minimum allowable joint probability this time is $(0.5)^{3}=0.125$.

Table 0.4 gives results for the case when the probability threshold at 0.45 is lowered slightly to 0.40 . Although the number of candidate items is increased by only 5 (from 22 at 0.45 to 27 at 0.40 ), the number of completed paths is more than doubled. Of particular note is the fact that scenarios other than those made up of states 2,5 and 8 now begin to emerge.

The LAMP POST approach is thus seen to have great flexibility. Indeed, if the threshold is set at zero, the algorithm degenerates into an exhaustive search of all $3^{3} * 3=162$ paths. Though it would be impractical to execute this option when a large number of variables is involved, it serves as a final arbiter to resolve any doubts which might arise in the application of the LAMP POST scheme.

And such doubts can arise!

For example, if one looks at the complete roster of 162 paths, one finds scenarios in the list of top events which, have higher movabilities that paths selected from thresholding at - say -0.40 or 0.45 . In Table 0.5 the top nine events are compared for thresholds of 0.4 and 0.0 . It is to be noted

\section{TABLE 0.2}

PROBABILITY THRESHOLD $=.45$
NUMBER OF CANDIDATE ITEMS $=22$

Event Conditial probabilities Joint vent probability

$\begin{array}{llll}258 & .5 & .53 & .57 \\ 528 & .45 & .57 & .53 \\ 582 & .45 & .57 & .56 \\ 825 & .5 & .56 & .53\end{array}$


TABLE D.3

$\begin{aligned} \text { PROBABILITY THRESHOLD } & =.5 \\ \text { NUMBER OF CANDIDATE ITEMS } & =22\end{aligned}$

Event Input probabilities

$\begin{array}{llll}258 & .5 & .53 & .57 \\ 825 & .5 & .56 & .53\end{array}$

Joint event probability

TABLE D.4

PROBABILITY THRESHOLD $=.4$

NUMBER OF CANDIDATE ITEMS $=27$

\begin{tabular}{|c|c|c|c|c|}
\hline Event & \multicolumn{3}{|c|}{ Input probabilities } & Joint event probability \\
\hline $\begin{array}{l}258 \\
275 \\
276 \\
284 \\
527 \\
528 \\
582 \\
825 \\
842\end{array}$ & $\begin{array}{l}.5 \\
.5 \\
.5 \\
.5 \\
.45 \\
.45 \\
.45 \\
.5 \\
.5\end{array}$ & $\begin{array}{l}.53 \\
.41 \\
.41 \\
.53 \\
.57 \\
.57 \\
.57 \\
.56 \\
.4\end{array}$ & $\begin{array}{l}.57 \\
.42 \\
.48 \\
.4 \\
.41 \\
.53 \\
.56 \\
.53 \\
.51\end{array}$ & $\begin{array}{l}.15105 \\
.0861 \\
.0984 \\
.106 \\
.105165 \\
.135945 \\
.14364 \\
.1484 \\
.102\end{array}$ \\
\hline
\end{tabular}

TABLE D.5

TOP NINE EVENTS EMERGING FROM TWO THRESHOLDINGS

$$
\text { Threshold }=0.40 \quad \text { Threshold }=0.0
$$

$\begin{array}{cclcl}\text { Rank } & \text { Event } & \text { Probability } & \text { Event } & \text { Probability } \\ 1 & 258 & 0.15105 & 258 & 0.15105 \\ 2 & 825 & 0.1484 & 825 & 0.1484 \\ 3 & 582 & 0.14364 & 582 & 0.14364 \\ 4 & 528 & 0.135945 & 528 & 0.135945 \\ 5 & 284 & 0.106 & 725^{\star} & 0.109445 \\ 6 & 527 & 0.105165 & 284 & 0.106 \\ 7 & 842 & 0.102 & 527 & 0.105165 \\ 8 & 276 & 0.0984 & 176^{\star} & 0.10416 \\ 9 & 275 & 0.0861 & 842 & 0.102\end{array}$

For this purpose, we need to go back to the component probabilities which make up the offending calculations (see Table D.6.) 
TABLE D.6

BASES FOR COMPUTING PROBABILITIES

OF TOP NINE EVENTS

AT 0.0 THRESHOLD

\begin{tabular}{lllll} 
Event & Final Prob. & \multicolumn{3}{c}{ Component Probabilities } \\
$25 \mathrm{~B}$ & 0.15105 & 0.5 & 0.53 & 0.57 \\
825 & 0.1484 & 0.5 & 0.56 & 0.53 \\
582 & 0.14364 & 0.45 & 0.57 & 0.56 \\
528 & 0.135945 & 0.45 & 0.57 & 0.53 \\
725 & 0.109445 & 0.35 & 0.59 & 0.53 \\
284 & 0.106 & 0.5 & 0.53 & 0.40 \\
527 & 0.105165 & 0.45 & 0.57 & 0.41 \\
176 & 0.10416 & 0.35 & 0.62 & 0.48 \\
842 & 0.10416 & 0.5 & 0.4 & 0.51
\end{tabular}

*States intruding the 0.4 threshold 1 ist

It is evident where the difficulty lies. Even though events 725 and 176 each contain a probability factor of 0.35 , which is below the original threshold of 0.4 , it is not much below the threshold and is "made up for" by the relatively high component probabilities accessible for the other two factors.

The possibility of this type of "cross-over" is, of course, the bane of any short-cut search for maximum-probability joint events. In the case of LAMP POST, however, there is a readily available strategy for control. It consists of setting the threshold as low as is permissible under running-time constraints, and then "skimming off" fewer than the available number of completed paths. Under such a strategy, the list of joint events which emerges will usually be longer than is practical to consider, but a long list insures that the top quarter - say - of the list will be essentially free from the risk of cross-over. (Note that, in Table D.5, the interjection of joint events 725 and 176 did not alter the dominance of the top four joint occurrences which emerged from the thresholding at 0.4.)

\section{D.2 IHE HIERARCHICAL ENVIRONMENT}

Consideration of cross-impact analysis in a hierarchical environment extends and modifies the mode of application already popular for BASICS, the fourunner of Doecim. This hierarchical mode of application places less emphasis on locating globally most-likely joint events and more emphasis on the 
conclusions reached when the system under study is initialized in a particular way.

Several difficulties with initializing on a particular state can be identified. First, as has been shown, selecting the highest conditional probability at each stage does not necessarily insure that the resulting joint event is most likely. Under certain conditions, choosing a less-than-maximum conditional probability at one stage may open up a path which gives access to relatively high conditional probabilities in subsequent stages, so much so that these latter probabilities compensate for the relatively low initial probability chosen at the outset. Second, one must question the efficacy of following a particular path through a conditional probability matrix as initialization would imply if two or more paths give joint probabilities which differ little from each other.

The Lamp Post algorithm can be applied to an initialized system in essentially the same way as it is applied to a non-initialized system. The only difference is that the initialized system is "degenerate" to a degree dependent upon the number of variables preset to selected states in the initialization phase of the analysis.

\section{D.2.1 Initialization on a Single Variable}

The BASICS algorithm considers initialization on each of the possible states of the system under study. For example, if there are $\mathrm{N}$ descriptors, each with three states, then $3 \mathrm{~N}$ initializations are possible. As initially conceived and practiced, BASICS also considered each of these states as "not occurring," but this phase of the analysis has been indicated to be redundant. For each initialization, the BASICS algorithm, by selecting the maximum conditional at each stage of the search, identifies a final outcome as the "consequence" of the initialization.

Application of the Lamp Post algorithm would not change, fundamentally, the strategy of the initialization approach. Instead of seeking, stepwise, the highest conditionals in a chain-wise sequence, one would threshold the conditionals (subject to the initialization) and then ask what chains can be completed among the thresholded subset of high-valued conditionals. Note 
that these chains might or might not include the chain derived by the BASICS approach.

Several advantages accrue from the Lamp Post strategy. First, it assures that there are no "sleepers" among the candidate, high-probability joint events. Second, if two or more paths give equal or nearly equal joint-event probabilities, these joint events would be identified and could be tagged for further study. Finally, the Lamp Post algorithm can be applied with considerable savings in the search space when initialization occurs. This holds, perforce, with more than one preinitialization.

\section{D.2.2 Higher-Order Initialization}

Higher-order initialization is a straightforward generalization of singlevariable initialization. For example, it may be of interest to know how the system responds when two or more variables are present to specific states. Such higher-order initialization simply increases the level of degeneracy of the problem For example, if two variables and applies the Lamp Post algorithm in the usual way. The application consists, as before, in seeing what chains can be formed among the thresholded states and selecting the joint event or events which exhibit the highest product(s) of probabilities.

Only one slight difficulty remains to be resolved. As has been noted earlier, if two or ore states are involved in the initialization, the sequential order of these states may be at issue. Note, however, that this issue in no way affects the search for chains among the non-initialized variables. Whatever chain emerges as "most likely" is the chain which persists under the initialization choice. This chain uniquely fixes the choice of states of the unutilized variables, and it is only to that part of the problem that the Lamp Post algorithm is addressed. Whether the initialized state of Variable 1 precedes that of Variable 2, or vice versa, must be determined by comparing the probability products involved in the two cases, subject to the assumptions made with regard to whether the impacts are to be interpreted in the causal or conditional sense.

The highest level of initialization in the hierarchy is represented by the situation in which all variables are preset to a particular state. The system is then completely degenerate, and the analysis simply yields a probability estimate for a specifically selected or hypothesized joint event. 
It is conceivable that this type of hypothesis might be of interest in certain types of analysis. For example, the approach would shed light on questions such as, "How likely is it that all of the following conditions would apply?" The hierarchical approach thus provides a complete gamut of possibilities for exploring impact relationships. 
PNL -6082

UC -13

DISTRIBUTION

No. of

Copies

OFFSITE

30 Technical Information Center

Bruce Cranford

Office of Industrial Programs

Majl Stop CE-12

Forrestal Building

U.S. Department of Energy

1000 Independence Avenue, S.W.

Washington, DC 20585

Barry McNutt

Office of Policy Integration

Mail Stop PE-40

Forrestal Building

U.S. Department of Energy

1000 Independence Avenue, S.W.

Washington, DC 20585

Harvey Major

office of Conservation

U.S. Department of Energy

Maj1 Stop CE-12

1000 Independence Avenue, S.W.

Washington, DC 20585

Ken Friedman

Office of Conservation

U.S. Department of Energy

Mail Stop CE-12

1000 Independence Avenue, S.W. Washington, DC 20585
No. of

Copies

OFFSITE

Fred Abel

Office of Building and Community Systems

U.S. Department of Energy

1000 Independence Avenue

Washington, DC 20585

Paul Werbos, Lead Analyst

Industrial Energy Demand

Energy Information Admin.

Mail Stop EI-621

Forrestal Building

1000 Independence Avenue, S.W.

Washington, DC 20585

Margaret Sibley, Director

Office of Policy Integration

U.S. Department of Energy

Mail Stop PE-15

Forrestal Building

1000 Independence Avenue, S.W.

Washington, DC 20585

Peggy Podolak

Office of Policy Integration

U.S. Department of Energy

Forrestal Building, Mail Stop PE-40

1000 Independence Avenue, S.W.

Washington, DC 20585

Vito Stagliano

Office of Policy Integration

U.S. Oepartment of Energy

Forrestal Building, Mail Stop PE-40

1000 Independence Avenue, S.W. Washington, DC 20585 
PNL -6082

UC -13

\section{DISTRIBUTION}

No. of

Copies

OFFSITE

Alex Haynes

Office of Policy Planning and Analysis

U.S. Department of Energy

1000 Independence Avenue, S.W.

Washington, DC 20585

David Meyer

Office of Coal and Electricity Policy

U.S. Department of Energy

1000 Independence Avenue, S.W.

Washington, DC 20585

Richard Holt

Office of Policy Integration

U.S. Department of Energy

1000 Independence Avenue, S.W.

Washington, DC 20585

Jerome Lamontagne

No. of

Copies

ONSITE

DOE Richland Operations office

J. J. Sutey

44 Pacific Northwest Laboratory

R. C. Adams

W. B. Ashton

D. B. Belzer

J. L. Braitman

J. W. Currie

W. T. Flynn

C. A. Geffen

M. L. Klan

R. J. Moe

J. M. Roop (20)

R. M. Scheer (5)

Economics Library (3)

Publishing Coordination (2)

Technical Information Center (5)

Brookhaven National Laboratory, Bldg 120

Upton, NY 11973

5 G. S. Stacey

Battelle Columbus Laboratory

505 King Street

Columbus, $\mathrm{OH} 43201$

H. T. McAdams

Box 150

Argenta, IL 62501 